\title{
Multiphase Multicomponent Numerical Modeling for Hydraulic Fracturing with N-Heptane for Efficient Stimulation in a Tight Gas Reservoir of Germany
}

\author{
Faisal Mehmood ${ }^{1,2,3}$, Michael Z. Hou $\left.{ }^{1,2}{ }^{(}\right)$, Jianxing Liao ${ }^{4,5, *}$, Muhammad Haris ${ }^{2,3}$, Cheng Cao 2,6 (D) \\ and Jiashun Luo ${ }^{1}$ \\ 1 Institute of Subsurface Energy Systems, Clausthal University of Technology, \\ 38678 Clausthal Zellerfeld, Germany; faisal.mehmood@tu-clausthal.de (F.M.); hou@tu-clausthal.de (M.Z.H.); \\ jiashun.luo@tu-clausthal.de (J.L.) \\ 2 Research Centre of Energy Storage Technologies, Clausthal University of Technology, 38640 Goslar, Germany; \\ muhammad.haris@tu-clausthal.de (M.H.); caochengcn@163.com (C.C.) \\ 3 Department of Petroleum \& Gas Engineering, University of Engineering \& Technology Lahore, \\ Lahore 54890, Pakistan \\ 4 College of Civil Engineering, Guizhou University, Guiyang 550025, China \\ 5 Guizhou Provincial Key Laboratory of Rock and Soil Mechanics and Engineering Safety, Guizhou University, \\ Guiyang 550025, China \\ 6 State Key Laboratory of Oil and Gas Reservoir Geology and Exploitation, Southwest Petroleum University, \\ Chengdu 610500, China \\ * Correspondence: jxliao@gzu.edu.cn
}

check for updates

Citation: Mehmood, F.; Hou, M.Z.; Liao, J.; Haris, M.; Cao, C.; Luo, J. Multiphase Multicomponent Numerical Modeling for Hydraulic Fracturing with N-Heptane for Efficient Stimulation in a Tight Gas Reservoir of Germany. Energies 2021, 14, 3111. https://doi.org/10.3390/ en14113111

Academic Editor: Reza Rezaee

Received: 30 March 2021

Accepted: 19 May 2021

Published: 26 May 2021

Publisher's Note: MDPI stays neutra with regard to jurisdictional claims in published maps and institutional affiliations.

Copyright: (c) 2021 by the authors. Licensee MDPI, Basel, Switzerland. This article is an open access article distributed under the terms and conditions of the Creative Commons Attribution (CC BY) license (https:/ / creativecommons.org/licenses/by/ $4.0 /)$.

\begin{abstract}
Conventionally, high-pressure water-based fluids have been injected for hydraulic stimulation of unconventional petroleum resources such as tight gas reservoirs. Apart from improving productivity, water-based frac-fluids have caused environmental and technical issues. As a result, much of the interest has shifted towards alternative frac-fluids. In this regard, n-heptane, as an alternative frac-fluid, is proposed. It necessitates the development of a multi-phase and multicomponent (MM) numerical simulator for hydraulic fracturing. Therefore fracture, MM fluid flow, and proppant transport models are implemented in a thermo-hydro-mechanical (THM) coupled FLAC3D-TMVOCMP framework. After verification, the model is applied to a real field case study for optimization of wellbore $\mathrm{x}$ in a tight gas reservoir using $\mathrm{n}$-heptane as the frac-fluid. Sensitivity analysis is carried out to investigate the effect of important parameters, such as fluid viscosity, injection rate, reservoir permeability etc., on fracture geometry with the proposed fluid. The quicker fracture closure and flowback of n-heptane compared to water-based fluid is advantageous for better proppant placement, especially in the upper half of the fracture and the early start of natural gas production in tight reservoirs. Finally, fracture designs with a minimum dimensionless conductivity of 30 are proposed.
\end{abstract}

Keywords: alternative frac-fluid; hydraulic fracturing; multiphase multicomponent; flowback; numerical modeling

\section{Introduction}

Continued development of new technologies has resulted in better exploitation of unconventional reservoirs, leading to efficient and expeditious production of petroleum resources. The increased petroleum production is attributed to advanced technologies of horizontal well drilling and hydraulic fracturing in tight gas reservoirs. Hydraulic fracturing has accounted for producing $50 \%$ of the natural gas and $33 \%$ of petroleum production in the U.S. [1-7].

Since inception, hundreds of thousands of fracturing operations have been performed [2,3,8-11]. Billions of liters of water have been utilized in these operations yearly 
because most of the treatments utilize water-based fluids with water as the main component $[3,12,13]$. Such high volumes of water create issues of water shortages, quality degradation, surface handling, and disposal [3,13-15]. Due to large water usage for hydraulic fracturing, public water resources and aquatic ecology are affected. The availability of water for population, agriculture and climate can be seriously impacted, especially in areas where susceptibility to droughts is high $[6,12,15,16]$. The contamination of the drinking water table by chemicals added to frac-fluids due to spills or leakages, disposal of improperly treated wastewater, etc. has been a growing concern [17]. In addition, technical issues such as delayed fracture closure leading to proppant settling at the bottom, can cause partial or even complete loss of borehole-fracture hydraulic connection (Figure 1). Lower flowback due to higher viscosity, density and entrapment leaving lower relative permeability for reservoir hydrocarbons, clay swelling in water-sensitive clays, and water retention in formations with sub-irreducible water saturation in tight reservoirs all result in inefficient fracturing operations [18-22]. Therefore, alternative fluids for hydraulic fracturing, such as foam-based, acid-based, alcohol-based, and gas-based, have been proposed. These fluids have their own limitations, such as surface handling, difficult rheological characterization, lower fracture conductivities, proppant placement issues, higher surface injection pressure requirements, and higher costs [18,23-25].

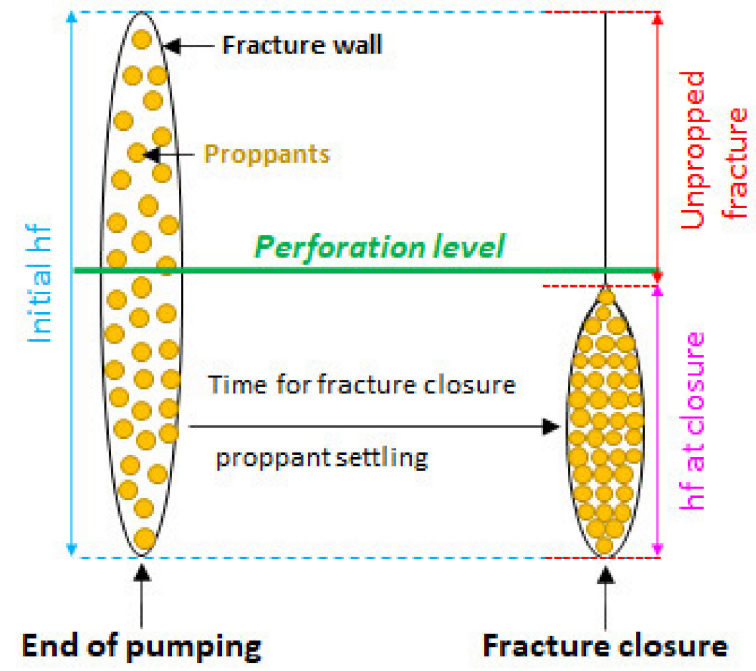

Figure 1. Illustration of inefficient proppant placement (hf: fracture height).

In this regard, a frac-fluid is proposed which consists of n-alkanes: pentane to decane $\left(\mathrm{C}_{n} \mathrm{H}_{2 n+2}: \mathrm{C}_{5}-\mathrm{C}_{10}\right)[26,27]$. Through this scheme, the use of water, as well as the environmental issues associated with it, can be largely minimized. The proposed fluid can be handled as a liquid at surface conditions and is compatible with the formation fluid as it is a petroleum product and hydrocarbon in nature. The density (ranging between $626-730 \mathrm{~kg} / \mathrm{m}^{3}$ ) and viscosity $(0.2-0.702 \mathrm{mPa} \cdot \mathrm{s})$ is also considerably less compared with water, therefore, the fracture closure and flowback can be significantly faster than water-based fluid. A single component, such as n-heptane, or a combination of different components according to different reservoir conditions can be used. As it is considerably less dense than water, the hybrid fluid concept, whereby initiating fracturing with $30-40 \mathrm{~m}^{3}$ water is followed by light alkanes injection, can help reduce large surface injection pressure requirements. The phase behavior of the individual components of the proposed fluid are shown in Figure 2.

The objective of this research is two-fold. Firstly, the development of a full 3D thermohydro-mechanical (THM) coupled numerical model to completely simulate the hydraulic fracturing process for a multi-phase multi-component (MM) fluid system. Secondly, the application of the numerical model to simulate hydraulic fracturing for the optimization of well $x$ in a tight gas reservoir in Germany with alternative frac-fluid (n-heptane) through 
sensitivity analysis of the most important parameters. However, it should be noted that hydraulic fracturing methods are not used industrially in Germany.

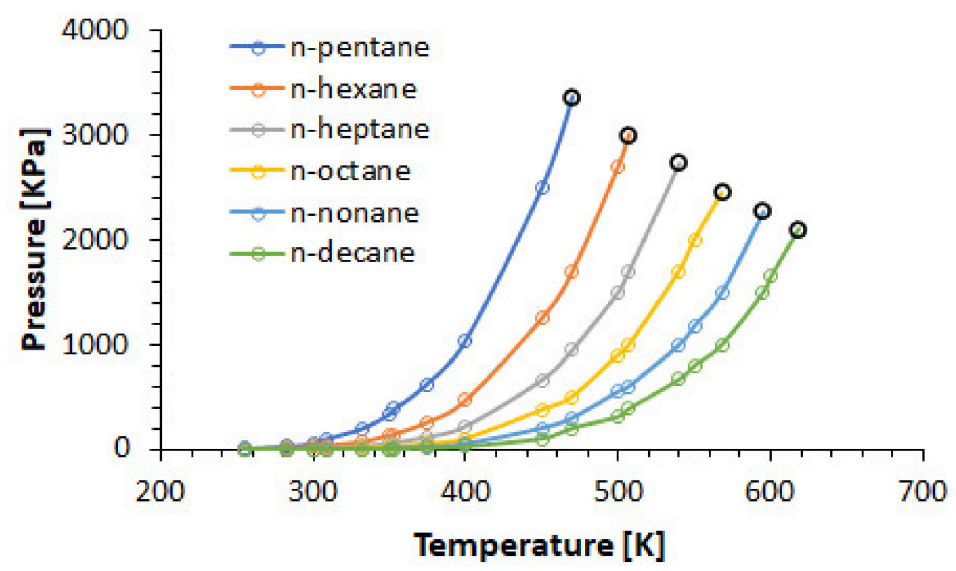

Figure 2. Phase behavior of individual components of n-alkanes. Last point (in black circle) on each curve represents respective critical point [28].

\section{Materials and Methods}

\subsection{N-Heptane as Frac-Fluid}

The tight gas reservoir considered for optimization in this study (discussed in Section 4) has a temperature range of more than $415 \mathrm{~K}$, therefore $\mathrm{n}$-heptane is selected as injection fluid as it has a boiling point of $371.6 \mathrm{~K}$. This temperature difference between reservoir and injection fluid causes fluid viscosity and density reduction due to the rise in fluid temperature following fluid-rock heat exchange. Some properties of n-heptane are presented in Table 1 and its phase behavior is shown in Figure 3 . The density of n-heptane is $689.5 \mathrm{~kg} / \mathrm{m}^{3}$ which is much lower than water. Therefore, to avoid excessive surface injection pressure requirements, a hybrid fluid concept will be utilized in this work, in which fracturing is initiated by injecting a small volume of water followed by an n-heptane injection.

Table 1. Important properties of n-heptane [29].

\begin{tabular}{ccccccc}
\hline Name & $\mathrm{C}_{\mathbf{n}} \mathbf{H}_{\mathbf{2 n + 2}}$ & $\begin{array}{c}\text { Critical } \\
\text { Temperature, K }\end{array}$ & $\begin{array}{c}\text { Critical Pressure, } \\
\text { MPa }\end{array}$ & $\begin{array}{c}\text { Boiling } \\
\text { Point, K }\end{array}$ & $\begin{array}{c}\text { Molecular Weight, } \\
\mathbf{g} / \mathbf{m o l}\end{array}$ & $\begin{array}{c}\text { Density @ 289 K, } \\
\mathbf{k g} / \mathbf{m}^{3}\end{array}$ \\
\hline n-heptane & $\mathrm{C}_{7} \mathrm{H}_{16}$ & 540.2 & 2.74 & 371.6 & 100.2 & 689.5 \\
\hline
\end{tabular}

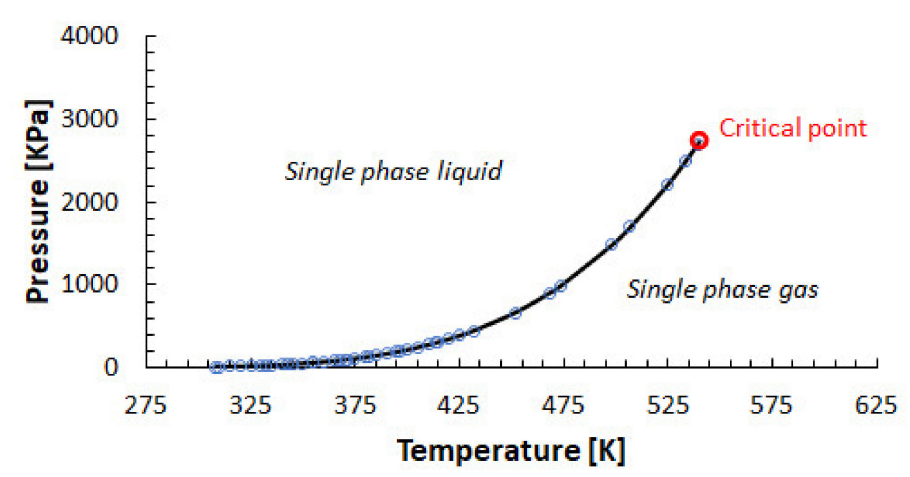

Figure 3. Phase behavior of n-heptane [28].

\subsection{Numerical Modeling}

Numerical modelling is a powerful tool to deal with the complex phenomenon of hydraulic fracturing. FLAC3D (fast Lagrangian analysis of continua in 3D) is a numerical modeling software which utilizes an explicit finite volume method to solve a wide 
variety of geotechnical problems [30]. Since FLAC3D deals with continuum mechanics, a new numerical 3D-model built on tensile fracture (discontinuous media) criterion in the presence of 3D stress state and hydromechanical coupling between fracture and matrix was developed by Zhou and Hou [31]. The effects of stress redistribution after the tensile failure and fluid leakoff to the matrix were all numerically modelled. To simulate proppant transport with gelled fluid, the solid-liquid two phase flow in the fracture was integrated, including proppant concentration, shear rate, fluid viscosity, proppant, and fluid densities, etc. [32]. These models were integrated into FLAC3D. The effect of reservoir heterogeneity on fracture orientation was also investigated in tight gas reservoirs using XFEM and FVM approaches [33]. To numerically study the heat transport in the fracture and heat exchange between the fracture and formation, a new thermal module was added to FLAC3D [34]. To model the THM processes in an MM environment, two well established numerical simulators, FLAC3D and TOUGH2, were coupled to exchange data with non-linear coupling functions [35-37]. The in-house upgraded version of FLAC3D, called FLAC3D ${ }^{\text {plus, }}$, was then coupled with TOUGH2MP to model hydraulic fracturing in different reservoirs such as oil, gas, and geothermal [37-40].

To simulate the hydraulic fracturing with n-heptane, it is important to model its behavior in the presence of formation fluids, i.e., water and gas. In addition, the determination of properties such as viscosity, density, and enthalpy, etc., of an alternative fluid at reservoir conditions is also imperative to properly understand its performance. Therefore, there is a need for a three-phase multi-component model which can simulate the flow of n-heptane as a separate phase in a non-isothermal environment. TMVOC (belonging to the family of TOUGH2) can model the MM flow of volatile organic chemicals in a non-isothermal manner [41]. Parameters such as saturation, relative permeability, viscosity, density, specific enthalpy, capillary pressure, and diffusion for every phase are considered and updated at each successful Newton-Raphson iteration. Hence, the appearance and disappearance of phases and components in different phases is modeled with reasonable accuracy.

Thus, numerical modeling of hydraulic fracturing with a variety of fluids (alternative and conventional) can be performed by coupling FLAC3Dplus (full 3D rock mechanical simulator) and TMVOC (reservoir simulator). In this approach, a fracture model, MM fluid flow model, and proppant transport model are implemented in the THM coupled FLAC3D ${ }^{\text {plus }}$-TMVOC framework $[38,39]$. In addition, fracture elements residing in the host matrix elements in a pre-defined path perpendicular to least principal stress are considered.

\subsubsection{Mechanical Deformation}

The main formulation utilized for mechanical calculations is based on FLAC3D. However, as the fracture is a discontinuous media, the discontinuous displacement due to tensile failure needed to be modelled. The flow in the fracture can be considered between two parallel plates. Continued injection of fluid after fracture initiation leads to the leakoff of fluid into the formation matrix from the fracture. Consequently, the pressure in the fracture changes. A simple bi-wing fracture can be observed in Figure 4.

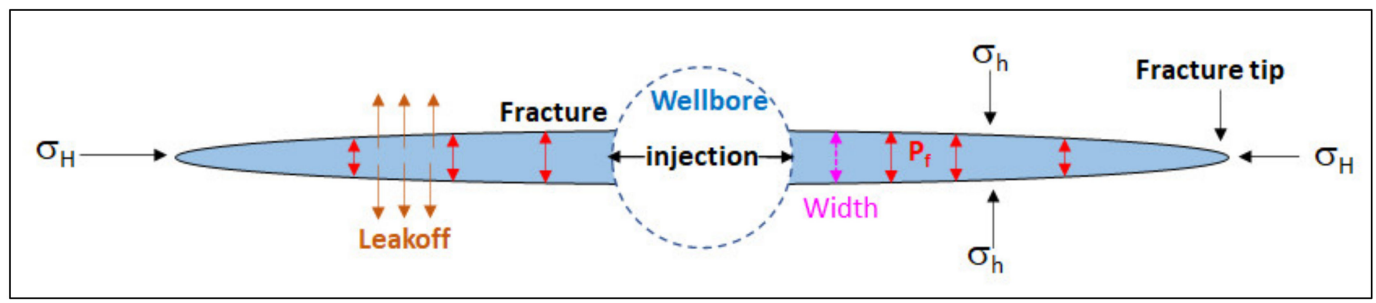

Figure 4. Top view of a bi-wing fracture in a vertical well.

In order to perform the mechanical calculations, FLAC3Dplus formulation, which relies upon the elasto-plasticity theory, is used. In this regard, the displacement increment in a time interval is determined by the solution of the equation of motion (Equation (1)). The 
strain and stress increments in a time step can be determined using the continuum and constitutive equations (Equations (2) and (3)) [30].

$$
\begin{gathered}
\sigma_{i j, j}+\rho\left(g_{i}-\frac{d v_{i}}{d t}\right)=0 \\
\Delta \varepsilon_{i j}=\frac{1}{2}\left(\Delta u_{i, j}+\Delta u_{j, i}\right) \\
\Delta \sigma^{\prime}=D \Delta \varepsilon
\end{gathered}
$$

where, $\sigma=\sigma^{\prime}-\alpha P_{m}$ (considering compressive stress positive); $\sigma$ : stress (Pa); $\sigma /$ : effective stress $(\mathrm{Pa}) ; \alpha$ : Biot's-coefficient $(-) ; P_{m}$ : reservoir pressure $(\mathrm{Pa}) ; \rho$ : density $\left(\mathrm{kg} / \mathrm{m}^{3}\right) ; g_{i}$ : gravitational acceleration $\left(\mathrm{m} / \mathrm{s}^{2}\right) ; v_{i}$ : velocity $(\mathrm{m} / \mathrm{s}) ; t$ : time $(\mathrm{s}) ; \Delta \varepsilon$ : strain increment $(-) ; u$ : displacement (m) $\Delta \sigma^{\prime}$ : effective stress increment; $D$ : physical matrix; $v$ : Poisson coefficient $(-) ; E$ : Elastic modulus (Pa); $v$ : Poisson's ratio (-); and $i, j \in(1,2,3)$.

$$
D=\frac{E}{(1+v)(1+2 v)}\left[\begin{array}{ccccccc}
1-v & v & v & & & \\
v & 1-v & v & & & \\
v & v & 1-v & & & \\
& & & 1-2 v & & \\
& & & & & 1-2 v & \\
& & & & & & 1-2 v
\end{array}\right]
$$

The tensile failure of the rock occurs when the injected fluid pressure exceeds the combined effect of the smallest principal stress and tensile strength. The fracture propagates in the path of least resistance, which is perpendicular to the least principal stress. Considering compressive stress to be positive, the failure criteria can be described as [31,32,42]:

$$
\sigma_{\min }-P_{f p}<-\sigma_{\text {tens }}
$$

$\sigma_{\text {min }}$ : minimum principal stress $(\mathrm{Pa}) ; \sigma_{\text {tens }}$ : tensile strength of rock $(\mathrm{Pa}) ;$ and $P_{f p}$ : pressure in fracture $(\mathrm{Pa})$.

Due to the fluid injection, the pressure inside the fracture changes, effectuating the deformation of fracture elements. Hence, strain change perpendicular to fracture is induced. This strain increment is dependent upon the pressure inside the fracture working against the normal compressive stress, which is mathematically expressed by Equation (5):

$$
\Delta \varepsilon_{f}=\frac{P_{f p}(t+\Delta t)-\sigma_{n}(t)}{\alpha_{1}}
$$

The fracture width increment due to strain change, considering the small width of the host element, is calculated as follows:

$$
\Delta w=\Delta \varepsilon_{f} l_{\mathcal{C}}
$$

where $\Delta \varepsilon_{f}$ : strain increment (-); $\alpha_{1}=K+4 G / 3$ (rock toughness); $P_{f p}(t+\Delta t)$ : pressure at new time step $(\mathrm{Pa}) ; \sigma_{n}(t)$ : normal stress at previous time step $\{\mathrm{Pa}) ; K$ : bulk modulus of rock $(\mathrm{Pa}) ; G$ : shear modulus $(\mathrm{Pa}) ; \Delta w$ : fracture width change $(\mathrm{m})$; and $l_{c}$ : width of the zone perpendicular to fracture $(\mathrm{m})$.

Injection pressure that is higher than the closure stress gives rise to width augmentation. However, as the fluid injection is stopped, the pressure inside the fracture decreases and the fluid leaks off to the formation, resulting in width reduction. To avoid complete fracture closure, proppants are injected which keep the fracture open. This requires the inclusion of contact stress in the strain increment Equation (5), which is written as:

$$
\Delta \varepsilon_{f}=\frac{P_{f p}(t+\Delta t)-\sigma_{c t}(t)-\sigma_{n}(t)}{\alpha_{1}}
$$


where,

$$
\sigma_{c t}: \text { contact stress }\left\{\begin{array}{c}
\sigma_{c t}(t+1)=0 \text { if } C \leq 0.65 \text { and } w \geq w_{\text {resd }} \\
\sigma_{c t}(t+1)=\sigma_{c o n}(t)+\alpha_{1} . \Delta \varepsilon_{0} \text { if } C>0.65 \text { and } w<w_{\text {resd }}
\end{array}\right.
$$

C: proppant concentration $\left(\mathrm{m}^{3} / \mathrm{m}^{3}\right) ; \Delta \varepsilon_{0}$ : over reduced strain $(-)$; and $w_{\text {resd }}$ : residual width (m).

The fracture propagation in this model utilizes the concept of subdividing the zones into fractured, partially fractured, and unfractured elements. The zone containing the fracture tip is crucial and is therefore further divided into sub-elements to enhance the precision of numerical modeling (Figure 5) [43]. Once enough sub-elements are fractured in an element, its status is changed to fractured element and the next element becomes the tip or partially fractured element. The zones beyond the fracture tip are considered unfractured.

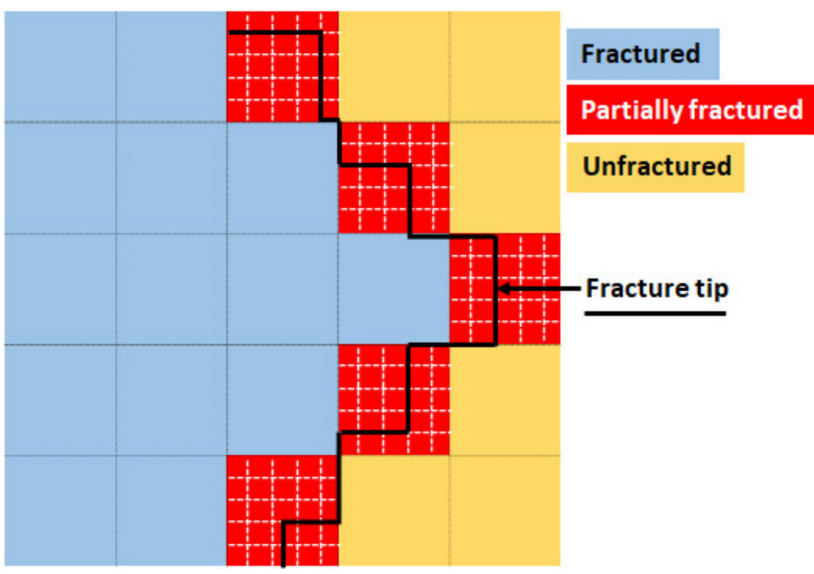

Figure 5. Zone subdivision categories and sub-elements in fracture tip.

\subsubsection{Multi-phase Multi-Component (MM) Fluid Flow and Proppant Transport}

For the MM flow of fluid in the fracture and matrix, TMVOC formulation is utilized [41]. The mass conservation for different components and phases is given as:

$$
\frac{\partial M^{\kappa}}{\partial t}=-\vec{\nabla} \cdot\left(\sum_{\beta} \vec{F}_{\beta} x_{\beta}^{\kappa}\right)+q^{\kappa}
$$

$M^{\kappa}$ : mass accumulation term for component $\mathrm{k}\left(\mathrm{mol} / \mathrm{m}^{3}\right) ; F_{\beta}$ : mass flux $\left(\mathrm{mol} / \mathrm{m}^{2} / \mathrm{s}\right) ; \beta$ : liquid/gas/NAPL (non-aqueous phase liquids) phase; $x_{\beta}^{\kappa}$ : component $k$ mole fraction in phase $\beta(-)$; and $q^{\kappa}$ : source or sink ( $\left.\mathrm{mol} / \mathrm{m}^{3} / \mathrm{s}\right)$.

Solving the MM flow problem requires space discretization. A model is divided into small discrete blocks and the integral finite difference method is used for averaging. A discrete volume element $(V n)$ in the system is shown in Figure 6, bounded by the closed surface $\Gamma n$. The interface area between blocks is represented by A (Figure 6). Then, surface integrals for mass or energy can be approximated by taking the integral of Equation (8).

$$
\int_{V_{n}} M^{k} d V_{n}=\int_{\Gamma n} F^{k} d \Gamma_{n}-\int_{V_{n}} q^{k} d V_{n}
$$

The mass of a component $\mathrm{k}$ includes its share from all the phases in which it is present. Mass accumulation for the formation (matrix) for different phases in the reservoir is based upon the following relation:

$$
M^{\kappa}=\phi \sum_{\beta} S_{\beta} \rho_{\beta} x_{\beta}^{\kappa}
$$

where $\phi$ : porosity (-); $S_{\beta}$ : saturation of phase $\beta(-)$; and $\rho_{\beta}$ : density of phase $\beta\left(\mathrm{mol} / \mathrm{m}^{3}\right)$. 
The flow simulation can be characterized into three categories, which include flow in fracture, flow between fracture and matrix, and matrix flow. The discrete elements are subdivided into matrix or reservoir elements and potential fracture elements. Darcy law governs the fluid flow in these elements, which can be written for a fluid phase $\beta$ as:

$$
\vec{F}_{\beta}=\rho_{\beta} u_{\beta}=-k \frac{k_{r \beta} \rho_{\beta}}{\mu_{\beta}}\left(\nabla P_{\beta}-\rho_{\beta} \vec{g}\right)
$$

$u_{\beta}$ : Darcy velocity $(\mathrm{m} / \mathrm{s}) ; k$ : permeability $\left(\mathrm{m}^{2}\right) ; k_{r \beta}$ : relative permeability of phase $\beta ; \mu_{\beta}$ : viscosity of phase $\beta(\mathrm{Pa} \cdot \mathrm{s}) ; \nabla P_{\beta}$ : pressure gradient $(\mathrm{Pa} / \mathrm{m})$; and $g$ : gravity $\left(\mathrm{m} / \mathrm{s}^{2}\right)$.

Due to hydraulic fracturing, a fracture with a certain width is present. Therefore, the mass conservation equation for a fracture involves the inclusion of fracture width to Equation (8), given by:

$$
F \frac{1}{w} \frac{\delta\left(w M^{k}\right)}{\delta t}=-\vec{\nabla}\left(\sum_{\beta} \vec{u}_{\beta} x_{\beta}^{\kappa}\right)+q^{\kappa}
$$

where, F: fraction of fractured sub-element: $\frac{\text { no. of fractured sub elements }}{\text { total no. of sub elements }}(-)$; and w: fracture width (m).

Fluid viscosity determination is of prime importance for determining the fluid flow behavior in porous media. During the hydraulic fracturing operation, the fluid viscosity is affected by gelling, proppant transport, shear and, especially, temperature variations. For mixture viscosity, the following relation is utilized in TMVOC:

$$
\mu_{n}=\prod \mu_{k}^{x_{n}^{k}}
$$

$\mu_{n}$ : viscosity of NAPL phase (Pa.s); $\mu_{k}^{x_{n}^{k}}:$ viscosity of component $k$ in NAPL mixture (Pa.s); and $x_{n}^{k}$ : mole fraction of component $k$ in NAPL phase.

For proppant transport and avoiding unnecessary fluid loss, fluids are normally gelled using guar gum. During the fracturing and proppant transport process, the fluid viscosity varies, accordingly the term apparent fluid viscosity is used which depends upon the shear rate, proppant concentration, and temperature differentials, etc. The following relations modified from Torres et al. and Zhang et al. $[44,45]$ are utilized for apparent viscosity to include the effect of shear rate, gelling agent concentration, and temperature variations:

$$
\begin{gathered}
\frac{\mu_{a p}}{\mu_{0}}=\frac{1}{1+k \gamma^{(1-n)}} \\
\mu_{0}=\left(a_{1} b_{1}\right)^{\ln \left(C_{g}\right)} \exp \left[\left(\frac{E a}{R}\right) \times\left(\frac{1}{T}-\frac{1}{T_{0}}\right)\right]
\end{gathered}
$$

where, $\mu_{a p}$ : apparent viscosity (Pa.s); $\mu_{0}$ : zero shear viscosity (Pa.s); $\gamma$ : apparent shear rate $(1 / \mathrm{s}) ; n$ : flow index; $a_{1}, b_{1}, k$ : constants $(-) ; C_{g}$ : guar concentration $(\mathrm{g} / \mathrm{l}) E_{a}$ : activation energy of viscous flow $(\mathrm{J} / \mathrm{mol}) ; R$ : ideal gas constant $(\mathrm{J} / \mathrm{mol} / \mathrm{K}) \mathrm{T}$ : temperature $(\mathrm{K})$; and $T_{0}$ : reference temperature $(\mathrm{K})$.

Once the proppant injection starts, the viscosity of the proppant-carrying slurry changes. Barre and Conway [46] presented the following correlation to include the effect of proppant concentration on fluid viscosity:

$$
\mu_{a p}=\mu_{0}\left(1-\frac{C_{p}}{C_{p \max }}\right)^{-a}
$$

$C_{p}$ : proppant concentration in the slurry (-); $C_{\text {pmax }}$ : maximum proppant concentration (-); and $a$ : correlation coefficient. 
To model the fluid flow including the effect of shear, temperature variation, gelling agent concentration, and proppant concentration on viscosity, the above equations are combined to give the new model as given by Equation (17) $[41,44,45]$ :

$$
\mu_{a p, \mu_{k}^{x_{n}^{k}}}=\left\{\left(a_{1} b_{1}\right)^{\ln \left(C_{g}\right)} \exp \left[\left(\frac{E a}{R}\right) \times\left(\frac{1}{T}-\frac{1}{T_{0}}\right)\right]\right\} \frac{1}{1+k \gamma^{(1-n)}}\left(1-\frac{C_{p}}{C_{p \max }}\right)^{-a}
$$

where $\mu_{a p, \mu_{k}^{x_{n}^{k}}}$ : apparent viscosity of proppant carrying fluid (component $\mathrm{k}$ ) in the NAPL phase.

The proppant-carrying slurry velocity and proppant settling velocity is found by the following set of equations [32]:

$$
\begin{gathered}
v_{\text {slurry }}=\left(1-C_{p}\right) v_{l}+C_{p} v_{p} \\
V_{\text {settling }}=\left\{\begin{array}{llr}
\frac{d_{p}^{2}\left(\rho_{p}-\rho_{f}\right) g}{18 \mu_{\text {ap }}} & \text { if } & R N_{p}<2 \\
\frac{0.79132 d_{p}{ }^{1.14}\left(\rho_{p}-\rho_{f}\right)^{0.71}}{\rho_{l}^{0.29} \mu_{a p} p^{0.43}} & \text { if } & 500>R N_{p}>2
\end{array}\right.
\end{gathered}
$$

where $v_{\text {slurry }}$ : proppant carrying slurry velocity $(\mathrm{m} / \mathrm{s}) ; C_{p}$ : proppant concentration (-); $v_{l}$ : fluid velocity $(\mathrm{m} / \mathrm{s}) ; v_{p}$ : proppant velocity $(\mathrm{m} / \mathrm{s}) ; V_{\text {settling }}$ : proppant settling velocity $(\mathrm{m} / \mathrm{s})$; $\rho_{p}$ : proppant density $\left(\mathrm{kg} / \mathrm{m}^{3}\right) ; \rho_{f}$ : fluid density $\left(\mathrm{kg} / \mathrm{m}^{3}\right) ; \mu_{a}$ : apparent viscosity $(\mathrm{Pa} \cdot \mathrm{s}) ;$ and $R N_{p}$ : particle Reynold's number: $\frac{d_{p} v_{p} \rho_{f}}{\mu_{a p}}$.

The injection of NAPL (n-heptane or other hydrocarbons) into a gas reservoir in the presence of connate water requires three-phase fluid modeling. To model the multi-phase flow, a modified version of Stone's three-phase relative permeability function (available in TMVOC) is applied as defined by the following equations [41,47]:

$$
\begin{gathered}
k_{r g}=\left[\frac{S_{g}-S_{g r}}{1-S_{w r}}\right]^{n} \\
k_{r w}=\left[\frac{S_{w}-S_{w r}}{1-S_{w r}}\right]^{n} \\
k_{r a}=\left[\frac{1-S_{g}-S_{w}-S_{a r}}{1-S_{g}-S_{w r}-S_{a r}}\right]\left[\frac{1-S_{w r}-S_{a r}}{1-S_{w}-S_{a r}}\right]\left[\frac{\left(1-S_{g}-S_{w r}-S_{a r}\right)\left(1-S_{w}\right)}{\left(1-S_{w r}\right)}\right]^{n}
\end{gathered}
$$

The injected fluid saturation is found as $S_{a}=1-S_{g}-S_{w}$ and $k_{r g}$ : gas phase relative permeability (-); $k_{r w}$ : water phase relative permeability (-); $k_{r a}$ : NAPL (alkane: n-heptane) phase relative permeability (-); $S_{g}$ : gas phase saturation (-); $S_{w}$ : water phase saturation (-); $S_{a}$ : NAPL (n-heptane) saturation (-); $S_{g r}$ : irreducible gas saturation (-); $S_{w r}$ : irreducible water saturation (-); and $S_{a r}$ : irreducible NAPL (n-heptane) saturation (-).

Moreover, the three-phase capillary function from Parker et al. [48] is used in the TMVOC for measuring the capillary pressure given by the following relations [41]:

$$
\begin{gathered}
P_{c g a}=-\frac{\rho_{w} g}{\alpha_{g a}}\left[\left(\overline{S_{l}}\right)^{\frac{-1}{n}}-1\right]^{\frac{1}{m}} \\
P_{c g w}=-\frac{\rho_{w g} g}{\alpha_{a w}}\left[\left(\overline{S_{w}}\right)^{\frac{-1}{m}}-1\right]^{\frac{1}{n}}-\frac{\rho_{w g}}{\alpha_{g a}}\left[\left(\overline{S_{l}}\right)^{\frac{-1}{m}}-1\right]^{\frac{1}{n}} \\
P_{c a w}=P_{c g w}-P_{c g a}
\end{gathered}
$$

where $\overline{S_{w}}=\frac{\left(S_{w}-S_{m}\right)}{\left(1-S_{m}\right)}, \overline{S_{l}}=\frac{\left(S_{w}+S_{n}-S_{m}\right)}{\left(1-S_{m}\right)}, m=1-\frac{1}{n}, P_{c g a}$ : capillary pressure gas-alkane (n-heptane), and $P_{c g w}$ : capillary pressure gas-water. 


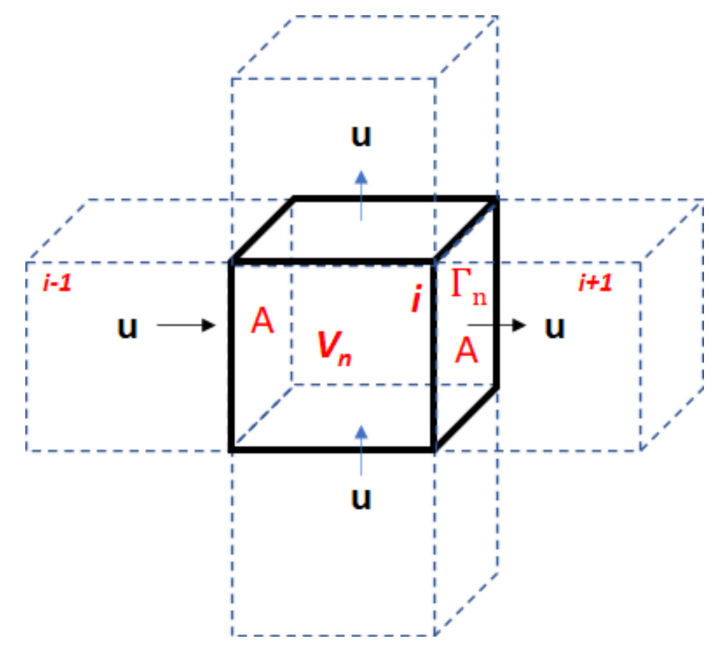

Figure 6. Space discretization concept with discrete element.

The fracturing, fluid flow and proppant transport models are implemented in the FLAC3D ${ }^{\text {plus }}$-TMVOC coupling. The data sharing between software and specific calculations performed at a time step can be observed in detail in Figure 7. The computing time of the simulation depends upon the size of 3D model, number of grid blocks, isothermal or non-isothermal process, number of components for injection and production, etc., and therefore may range from a few hours to a few days.

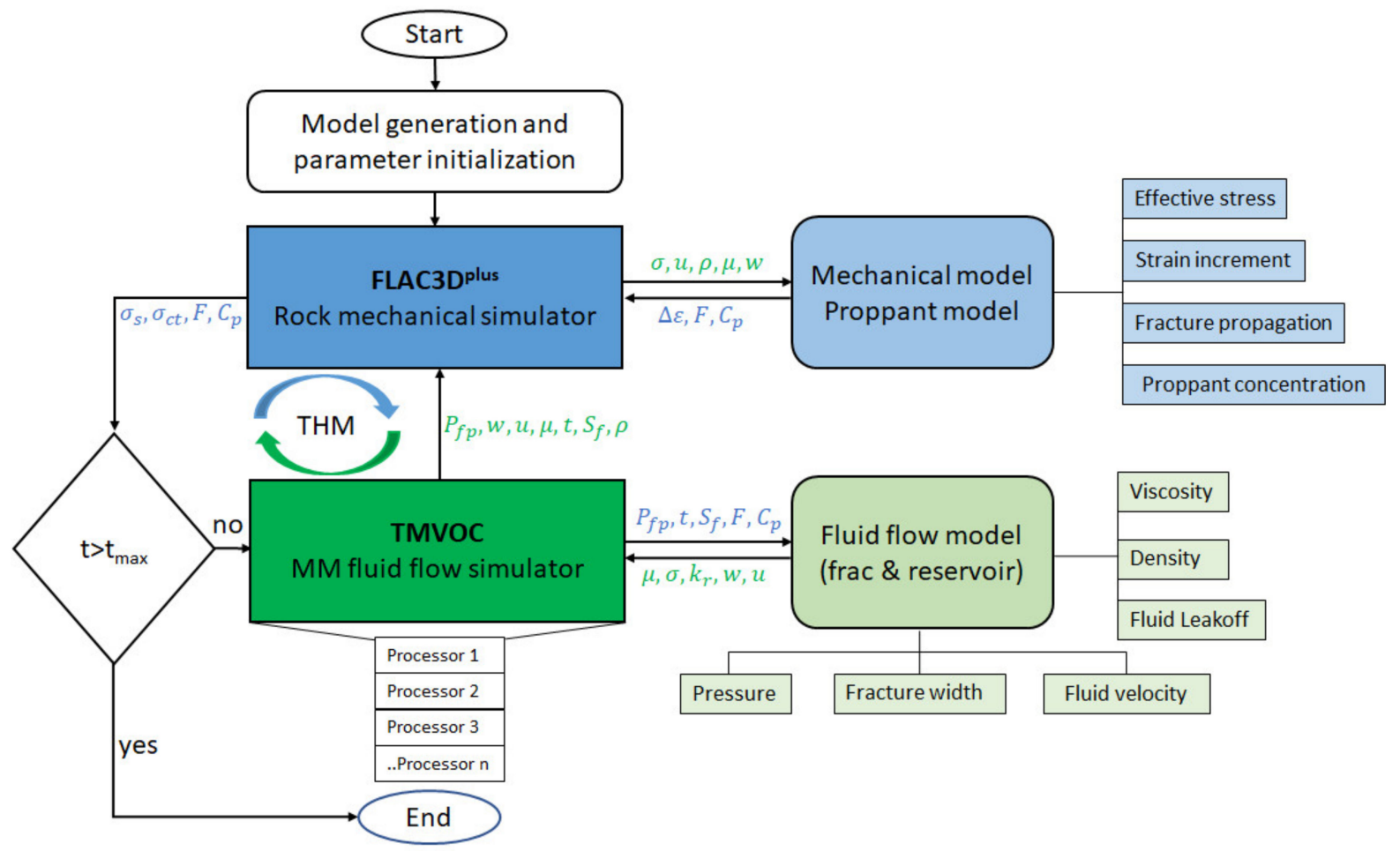

Figure 7. Software coupling and data sharing. $\left(\sigma_{s}\right.$ : stress state, $u$ : fluid velocity, $\rho$ : density, $\mu$ : viscosity, $w$ : width, and $S_{f}$ : fluid saturation).

\section{Verification of Developed Numerical Model}

The verification is divided into the following three parts:

- Fracturing ability;

- Non-isothermal flow;

- Proppant transport. 


\subsection{Fracturing Ability}

Hydraulic fracturing was performed in the GeneSys (Generated Geothermal Energy Systems) project in which two wells were drilled. For the purpose of verification, one well, Gross Buchholz Gt1 drilled in 2009, was considered. Hydraulic fracturing was performed to generate high permeability flow paths for heat production. Massive hydraulic fracturing treatment, injecting $20,000 \mathrm{~m}^{3}$ of fresh water with five injection-shutin cycles, was carried out to create a fracture area of more than $0.5 \mathrm{~km}^{2}$ [49].

To validate the hydraulic fracturing ability of the numerical model, the first hour of injection was simulated and matched with published results, although $106 \mathrm{~h}$ of injection were carried out to complete the massive fracturing operation. The generated 3D quarter model in FLAC3D, as per the available geological data, can be observed in Figure 8a. The generated model lies between the depth of $-3287 \mathrm{~m}$ to $-3850 \mathrm{~m}$ and has dimensions of $1700 \mathrm{~m} \times 350 \mathrm{~m}$ in the $\mathrm{x}-\mathrm{y}$ plane, respectively. The reservoir pressure and stress state can be observed in Figure $8 b[39,49]$.

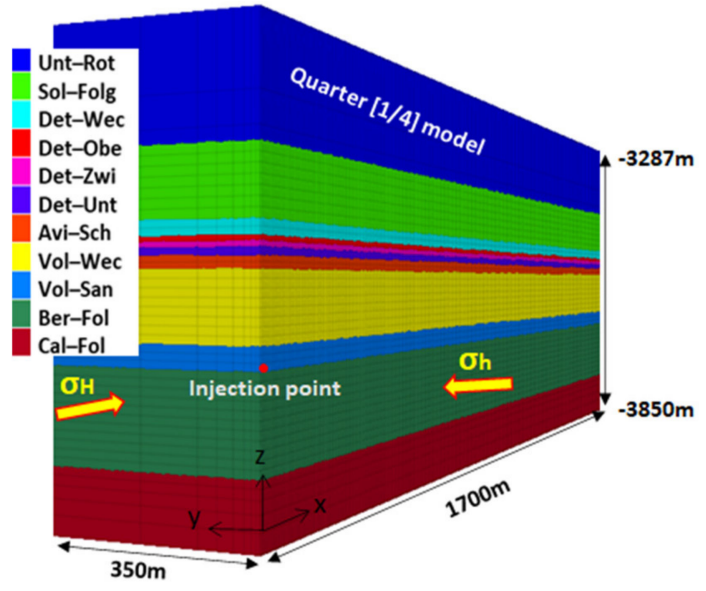

(a)

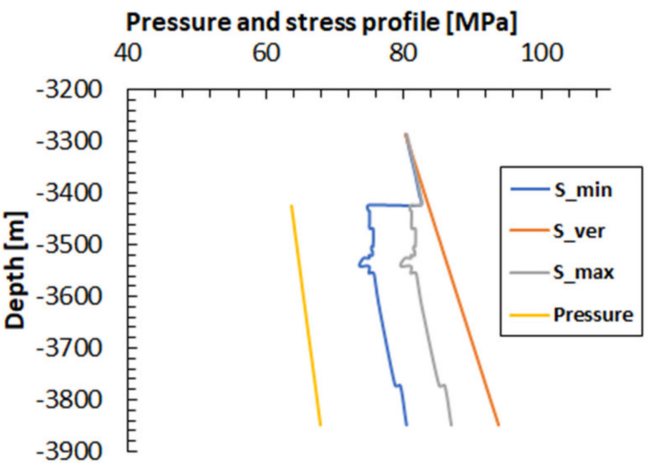

(b)

Figure 8. The (a) 3D quarter geological model, and (b) stress state and pressure profile in the model, s_min: minimum horizontal stress, s_ver: vertical stress, and s_max: maximum horizontal stress.

The simulated bottom-hole fracture pressure was matched with published data [38]. The pressure rose initially for fracture initiation by overcoming the minimum horizontal stress and tensile strength of the rock and then normalized during the propagation stage. However, it remained slightly higher than $80 \mathrm{MPa}$ during the simulation period of $1 \mathrm{~h}$ (Figure 9).

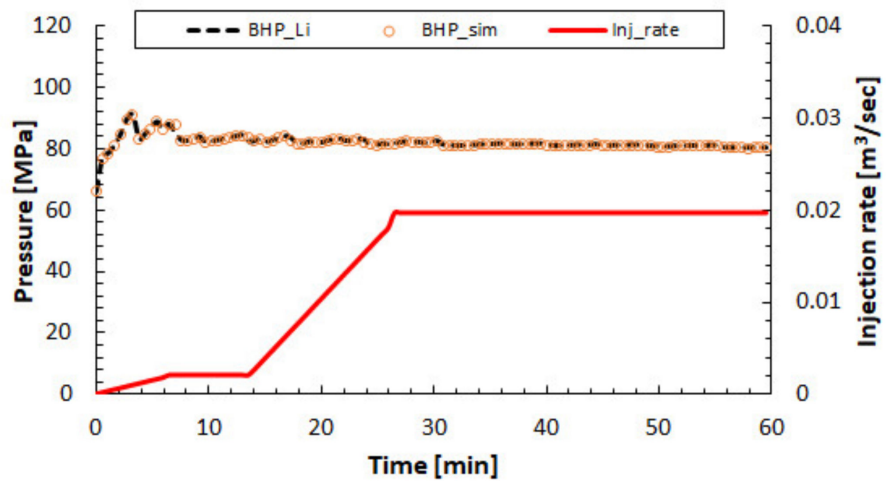

Figure 9. Fracture pressure comparison for simulation results and published data [39], sim: simulated, meas: measured, and inj_rate: injection rate. 


\subsection{Non-Isothermal Flow}

To validate the model for its ability to simulate multi-phase multi-component nonisothermal flow of fluids in porous media, displacement of the Benzene-Toluene mixture in a column with steam was carried out [41]. It involved the injection of benzene and toluene in a column, followed by water flood and subsequent steam flood. The sand column properties can be found in Table 2.

Table 2. Properties of sand column.

\begin{tabular}{cc}
\hline \multicolumn{2}{c}{ Model Properties } \\
\hline Porosity & $38.5 \%$ \\
Permeability & $1.6 \times 10^{-11} \mathrm{~m}^{2}$ \\
Initial pressure & $101.3 \times 10^{3} \mathrm{~Pa}$ \\
Temperature & $295.15 \mathrm{~K}$ \\
\hline
\end{tabular}

Figure 10 presents the variations in saturations of gas, water, and NAPL phases (threephase). It can be observed that the initial high saturation of NAPL changed and shifted downward in the column due to water injection. In addition, steam injection vaporized the fluid. The NAPL bank was reduced from grid block 38 to 42 . Additionally, due to high solubility, benzene was initially depleted. The effect on the temperature of the laboratory column after $5000 \mathrm{~s}$ of steam injection could also be observed. The temperature in grid block 36 reached $373.15 \mathrm{~K}$, whereas the temperature in grid block 45 was still at $295.15 \mathrm{~K}$, which was the initial temperature of the column.

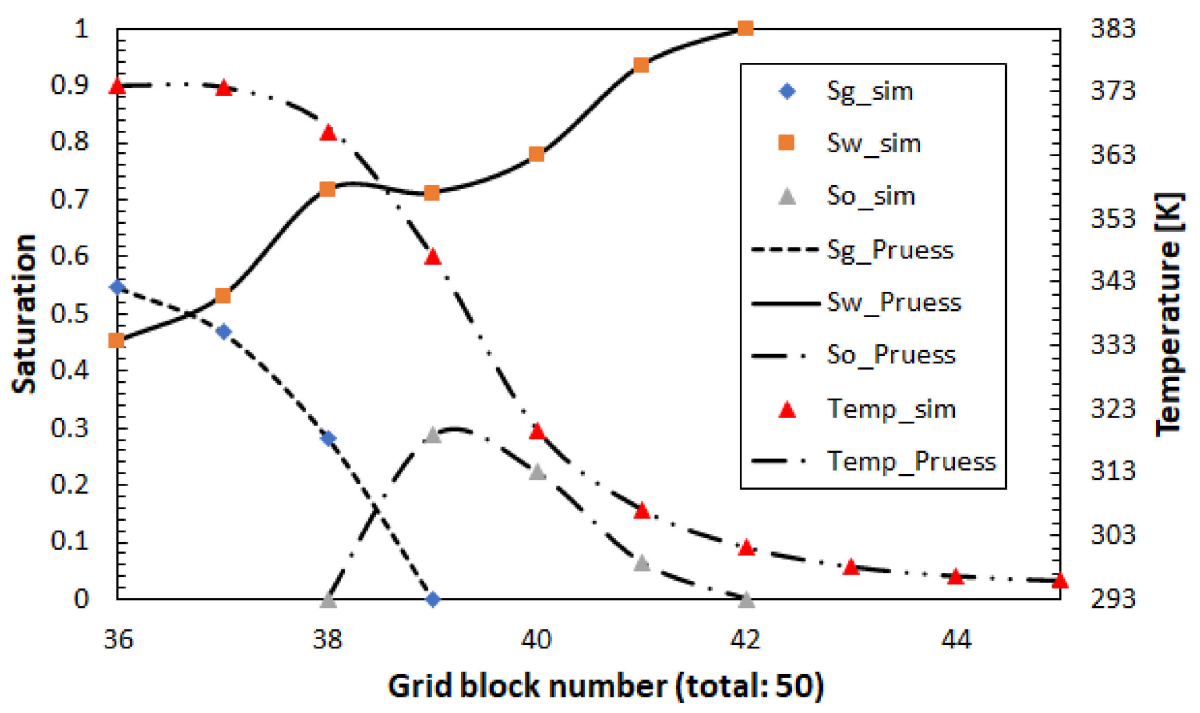

Figure 10. Comparison between simulation results and Pruess and Batistelli [41,50]. Sg: gas saturation, Sw: water saturation, So: NAPL saturation, and Temp: temperature.

Isothermal flow was considered in the first and second stage of injection. The first stage involved the injection of NAPLs into the 15th grid block from the top in the laboratory column. In the second stage, water was injected from the top for displacement. As can be observed in Figure 11, the maximum saturation of NAPLs reached about $40 \%$ before the water-flood. Soon after the water-flood, the saturation of NAPLs continued decreasing until the end of the injection to below $5 \%$. 


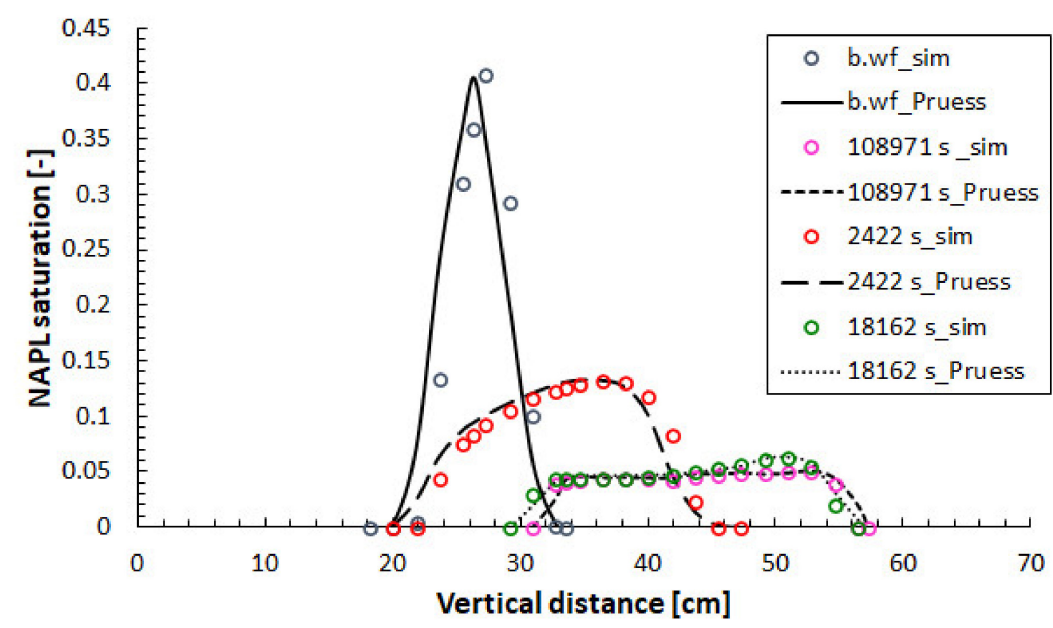

Figure 11. Comparison between simulation results and Pruess and Batistelli [41,50]. (b.wf: before water flood, and sim: simulated).

\subsection{Proppant Transport}

The modelling of proppant transport and settling was verified by matching it with published data $[32,46,51]$, through modelling the proppant transport and settling in a large slot. Table 3 summarizes the utilized properties of fluid, proppant, and injection rate, etc.

Table 3. Parameters for fluid and proppant.

\begin{tabular}{ccc}
\hline Parameter & Unit & Value \\
\hline Injection rate & $\mathrm{m}^{3} / \mathrm{sec}$ & $0.252 \times 10^{-3}$ \\
Proppant density & $\mathrm{kg} / \mathrm{m}^{3}$ & 2650 \\
Liquid density & $\mathrm{kg} / \mathrm{m}^{3}$ & 1035 \\
Proppant concentration in injection fluid & $\mathrm{kg} / \mathrm{m}^{3}$ & 479.36 \\
Fluid viscosity & $\mathrm{Pa} \cdot \mathrm{s}$ & 0.35 \\
Proppant diameter & $\mathrm{mm}$ & 0.6 \\
Power law coefficient & - & 0.65 \\
Parameter for viscosity correction & - & 1.8 \\
Maximal proppant concentration & - & 0.65 \\
\hline
\end{tabular}

A 3D model $(4.8768 \mathrm{~m} \times 0.0079 \mathrm{~m} \times 1.2192 \mathrm{~m})$ was generated in FLAC3D and similar conditions of proppant and liquid density, proppant concentration and, injection rate, etc., were utilized. The simulation was performed by injecting proppant, with a density of $2650 \mathrm{~kg} / \mathrm{m}^{3}$, with guar gel in the model at a height of about $0.914 \mathrm{~m}$ from the base (Figure 12). The simulation was carried out for a period of $150 \mathrm{~s}$ and injection rate and proppant concentration were maintained at $0.252 \times 10^{-3} \mathrm{~m}^{3} / \mathrm{sec}$ and $479.36 \mathrm{~kg} / \mathrm{m}^{3}$, respectively [52].

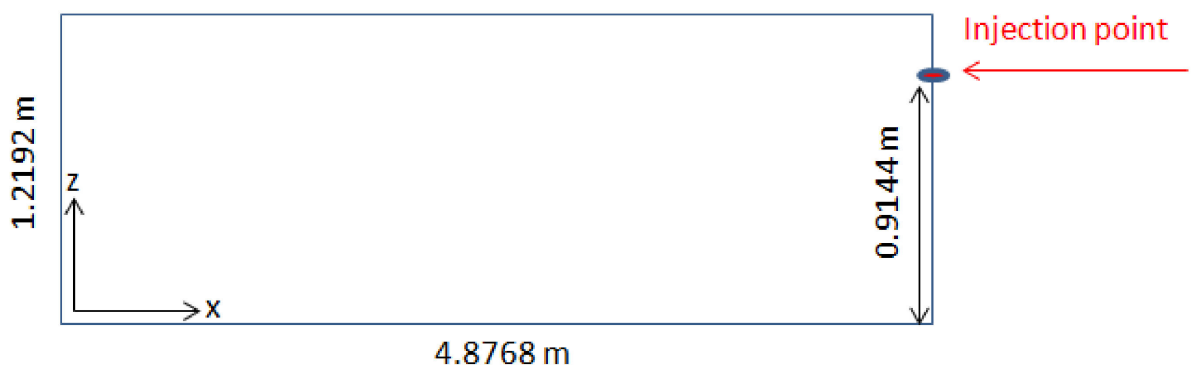

Figure 12. Schematic diagram of model for proppant transport. 
The profile of the simulated proppant transport and settling was recorded for different time points and the contours are presented in Figure 13. Analogous settling profiles were obtained while comparing them with numerical results [51]. The contours at 5,10 and $150 \mathrm{~s}$ showed a very good match, while a slightly different proppant settling profile was observed at $100 \mathrm{~s}$.

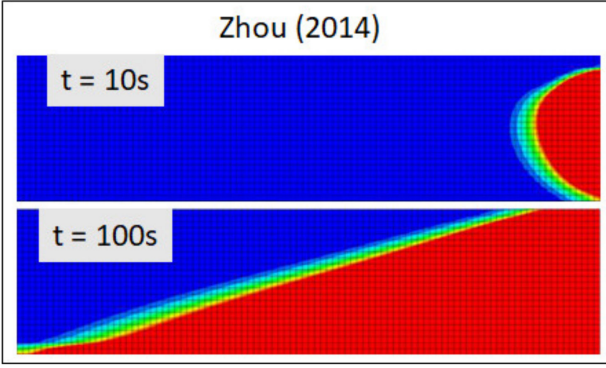

(a)

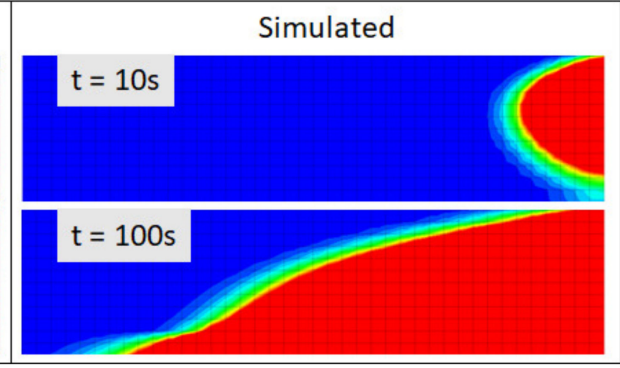

(b)

Figure 13. Proppant distribution contours at 10 and $100 \mathrm{~s}$, (a) numerical [51] and (b) simulated (developed numerical model).

In addition, a comparison was also made with the experimental results (Figure 14). It can be observed that simulated proppant transport and settling was in reasonable agreement with the experimental and numerical published data [32,46,51].
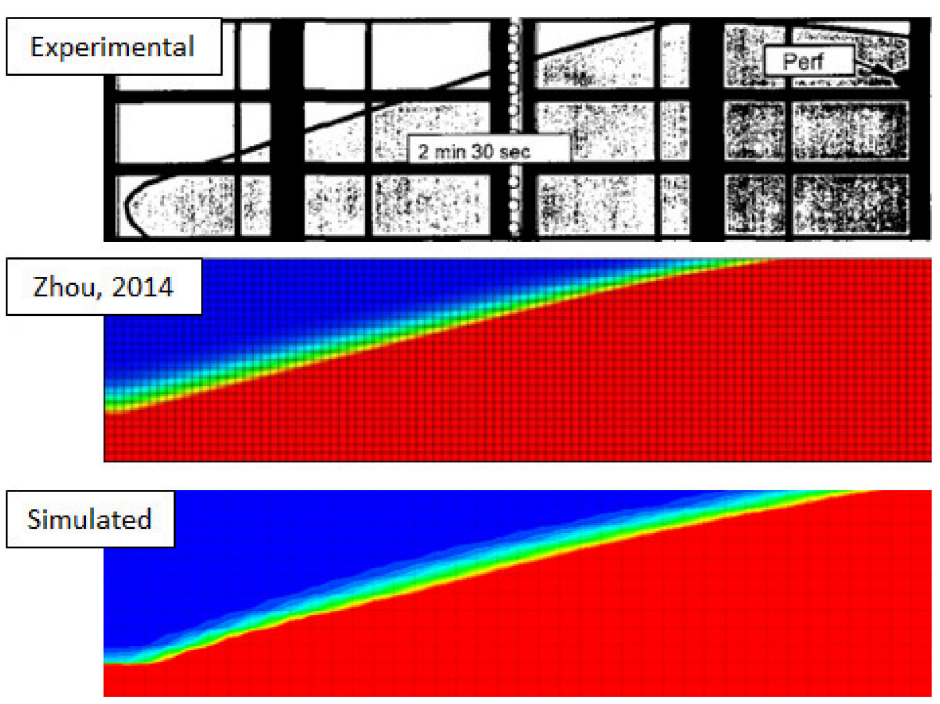

Figure 14. Proppant transport comparison at $150 \mathrm{~s}$ for experimental and numerical results.

\section{Case Study}

In this section, a case study for a wellbore $\mathrm{x}$ in a tight gas reservoir in Germany is presented. According to the $\mathrm{P} / \mathrm{Z}$ analysis, the reservoir had initial reserves of 645 million $\mathrm{m}^{3}$. A bottom-hole temperature and pressure of $423.15 \mathrm{~K}$ and $67 \mathrm{MPa}$, respectively, were recorded. Hydraulic fracturing was performed in the year 2000 targeting the Wustrow, Dethlingen and Havel formations. However, there was no significant productivity increase, and the production continued only for a few months with intermittent shutin periods recovering only around 2 million $\mathrm{m}^{3}$ gas. Considering homogenous conditions, a quarter $(1 / 4) 3 \mathrm{D}$ geometric model of the reservoir was generated. Figure 15a,b present the 3D model and pressure and stress profile of the reservoir. 


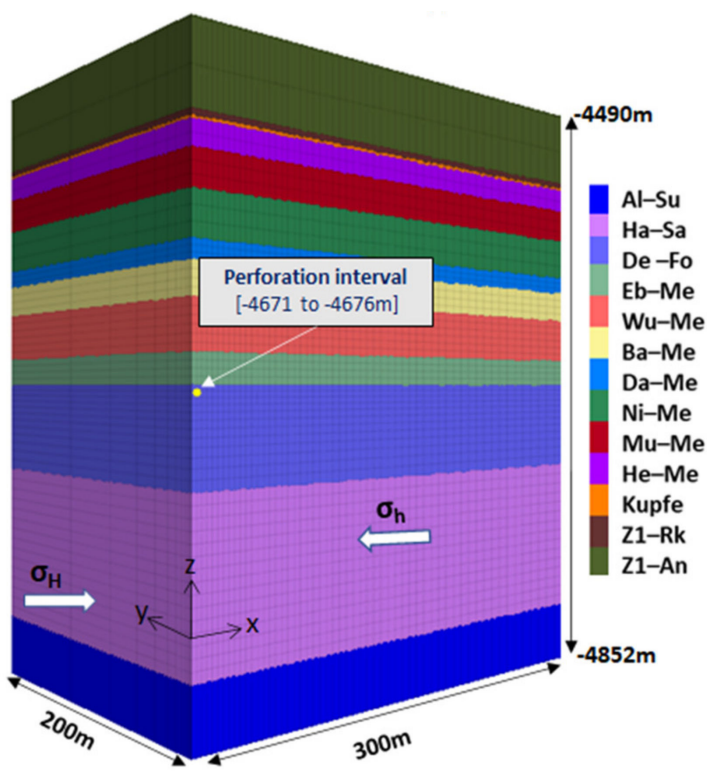

(a)

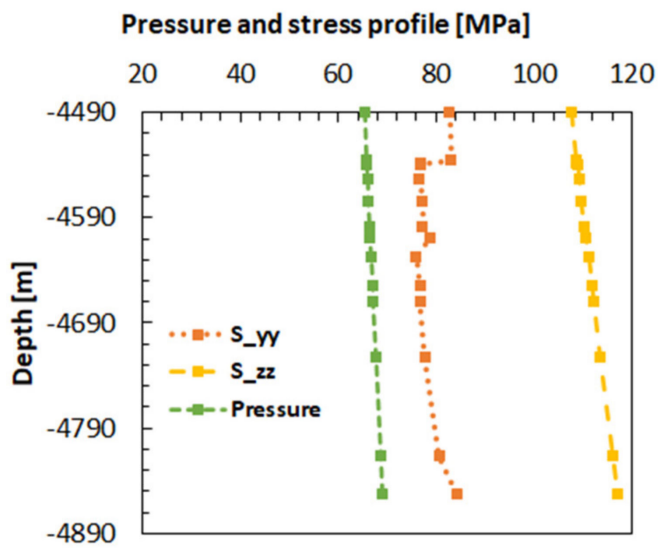

(b)

Figure 15. The (a) 3D geometric (1/4) model, and (b) pressure and stress in the model, S_yy: minimum horizontal stress, S_zz: vertical stress.

It is a multilayer reservoir; the perforations are located at depths of $4671.4-4676.2 \mathrm{~m}$. From breakdown and minifrac testing, the breakdown and frac gradient were determined to be $0.213 \mathrm{MPa} / 10 \mathrm{~m}$ and $0.175 \mathrm{MPa} / 10 \mathrm{~m}$, respectively, and the closure stress was measured as $80.82 \mathrm{MPa}$. The formation properties, obtained from core analysis and well logging, are summarized in Table 4.

Table 4. Properties of the formations.

\begin{tabular}{ccccccc}
\hline Formation & $\begin{array}{c}\text { Top Depth } \\
(\mathbf{m})\end{array}$ & $\begin{array}{c}\text { Young's Modulus } \\
\mathbf{( P a )}\end{array}$ & $\begin{array}{c}\text { Poisson's Ratio } \\
\mathbf{( - )}\end{array}$ & $\begin{array}{c}\text { Porosity (-) } \\
\text { Permeability } \\
\left(\mathbf{m}^{\mathbf{2}}\right)\end{array}$ & $\begin{array}{c}\text { Density } \\
\left(\mathbf{k g} / \mathbf{m}^{\mathbf{3}}\right)\end{array}$ \\
\hline Z1-An & 4490 & $2.90 \times 10^{10}$ & 0.275 & 0.041 & $9.720 \times 10^{-21}$ & 2940 \\
Z1-Rk & 4535 & $2.85 \times 10^{10}$ & 0.253 & 0.044 & $4.84 \times 10^{-17}$ & 2840 \\
Kupfe & 4538 & $2.89 \times 10^{10}$ & 0.260 & 0.059 & $3.15 \times 10^{-19}$ & 2715 \\
$\mathrm{He}-\mathrm{Me}$ & 4540 & $2.94 \times 10^{10}$ & 0.255 & 0.040 & $1.05 \times 10^{-16}$ & 2705 \\
$\mathrm{Mu}-\mathrm{Me}$ & 4554 & $3.06 \times 10^{10}$ & 0.206 & 0.068 & $2.78 \times 10^{-16}$ & 2655 \\
$\mathrm{Ni}-\mathrm{Me}$ & 4574 & $3.72 \times 10^{10}$ & 0.220 & 0.001 & $1.00 \times 10^{-21}$ & 2750 \\
$\mathrm{Da}-\mathrm{Me}$ & 4598 & $3.31 \times 10^{10}$ & 0.230 & 0.081 & $1.154 \times 10^{-16}$ & 2574 \\
$\mathrm{Ba}-\mathrm{Me}$ & 4609 & $3.01 \times 10^{10}$ & 0.197 & 0.110 & $1.165 \times 10^{-16}$ & 2500 \\
Wu-Me & 4627 & $2.93 \times 10^{10}$ & 0.2025 & 0.110 & $4.887 \times 10^{-16}$ & 2493 \\
Eb-Me & 4654 & $2.76 \times 10^{10}$ & 0.200 & 0.110 & $8.430 \times 10^{-16}$ & 2707 \\
De-fo & 4670 & $2.65 \times 10^{10}$ & 0.1975 & 0.113 & $5.79 \times 10^{-16}$ & 2668 \\
$\mathrm{Ha}-\mathrm{Sa}$ & 4723 & $2.61 \times 10^{10}$ & 0.2267 & 0.113 & $9.504 \times 10^{-16}$ & 2668 \\
$\mathrm{Al}-\mathrm{Su}$ & 4816 & $2.92 \times 10^{10}$ & 0.25 & 0.064 & $1.067 \times 10^{-20}$ \\
\hline
\end{tabular}

The geometric model was first verified by history matching with previous frac job. According to the pumping schedule, a total of $\sim 424.592 \mathrm{~m}^{3}$ fluid and 120 -ton $3465 \mathrm{~kg} / \mathrm{m}^{3}$ density proppants were injected. The injection continued for a period of $150 \mathrm{~min}$. The injection rate remained low until $63 \mathrm{~min}$ and then gradually increased to $4.89 \mathrm{~m}^{3} / \mathrm{min}$. A proppant slug at $5 \mathrm{ppg}$ (pounds/gallon) $\left(=599 \mathrm{~kg} / \mathrm{m}^{3}\right)$ was initially placed to remove the existing tortuosity. Afterwards, the proppant injection began at $96 \mathrm{~min}$ and was increased to a maximum proppant concentration of $7 \mathrm{ppg}\left(=839 \mathrm{~kg} / \mathrm{m}^{3}\right)$ at the end. As per the main frac data, the simulation of the fracking operation was performed with the developed 
model. Figure 16 presents the bottom-hole pressure (BHP) match of the simulated frac job with measured data.

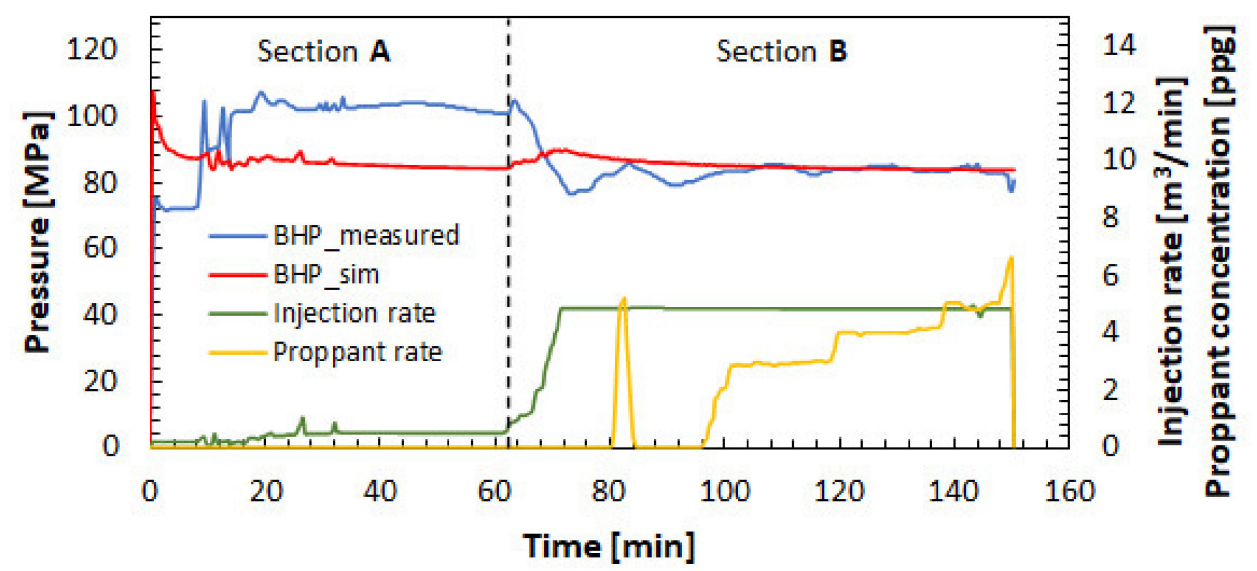

Figure 16. History match (BHP_sim) with measured BHP, injection rate and proppant schedule plotted for the main fracturing treatment.

After pumping only $23.2 \mathrm{~m}^{3}$ of injection fluid, the radiator shaft on the blender sheared off. Thus, the operation had to be stopped and commenced the following day. Due to the presence of still $x$-linked gel in the tubing, high tubing pressures were recorded and the first $2 \mathrm{~m}^{3}$ of fluid could only be injected at $0.2 \mathrm{~m}^{3} / \mathrm{min}$. The crosslinker was switched off and displacement was carried out with linear gel, however, the injection rates remained below $0.6 \mathrm{~m}^{3} / \mathrm{min}$ until the first $60 \mathrm{~min}$. Consequently, a pressure match was not feasible due the abnormal pressure recorded, as depicted in section A of Figure 16. Afterwards, the pressure finally dropped, and the injection rate was increased. It can be observed that a reasonable pressure match was obtained during the main course of injection (Figure 16, section $\mathrm{B})$.

The simulation was continued after shutin until $10 \mathrm{~h}$ to observe complete fracture closure. Figure 17 shows that the maximum fracture half-width reduced from the initial value of $0.007 \mathrm{~m}$ to $0.0024 \mathrm{~m}$ at closure. The fracture aperture decreased until the fracture walls came in contact with the proppants. Due to large closure time, the proppants settled to the bottom of fracture, depriving the upper half of the fracture of proppants. Consequently, the fracture width was very low at the level of perforations and the propped fracture height was even below the injection level away from the wellbore. Therefore, the fracture could not contribute efficiently towards production and may be a major reason behind the lower production from wellbore $x$.

In addition, the viscosity contour of the injected fluid can be observed in Figure 17. The injected fluid viscosity reduced from $0.205 \mathrm{~Pa} \cdot \mathrm{s}$ to about $0.02 \mathrm{~Pa} \cdot \mathrm{s}$ due to the gel break. The temperature of the fluid in the fracture remained low, especially near the injection zone, as fluid was continuously injected at surface temperature conditions. Thus, the highest viscosity contour at shutin was in the region of the lowest temperature. However, due to the temperature difference between fluid and formation, heat exchange took place, which raised its temperature. The temperature profile showed that the temperature increased from about $40{ }^{\circ} \mathrm{C}(313 \mathrm{~K})$ to the reservoir's initial temperature range, which lead to gel beak. After shutin, the fracture closure, due to leakoff, reduced the fracture volume from an initial volume of $280 \mathrm{~m}^{3}$ to $56 \mathrm{~m}^{3}$ (Figure 18). 

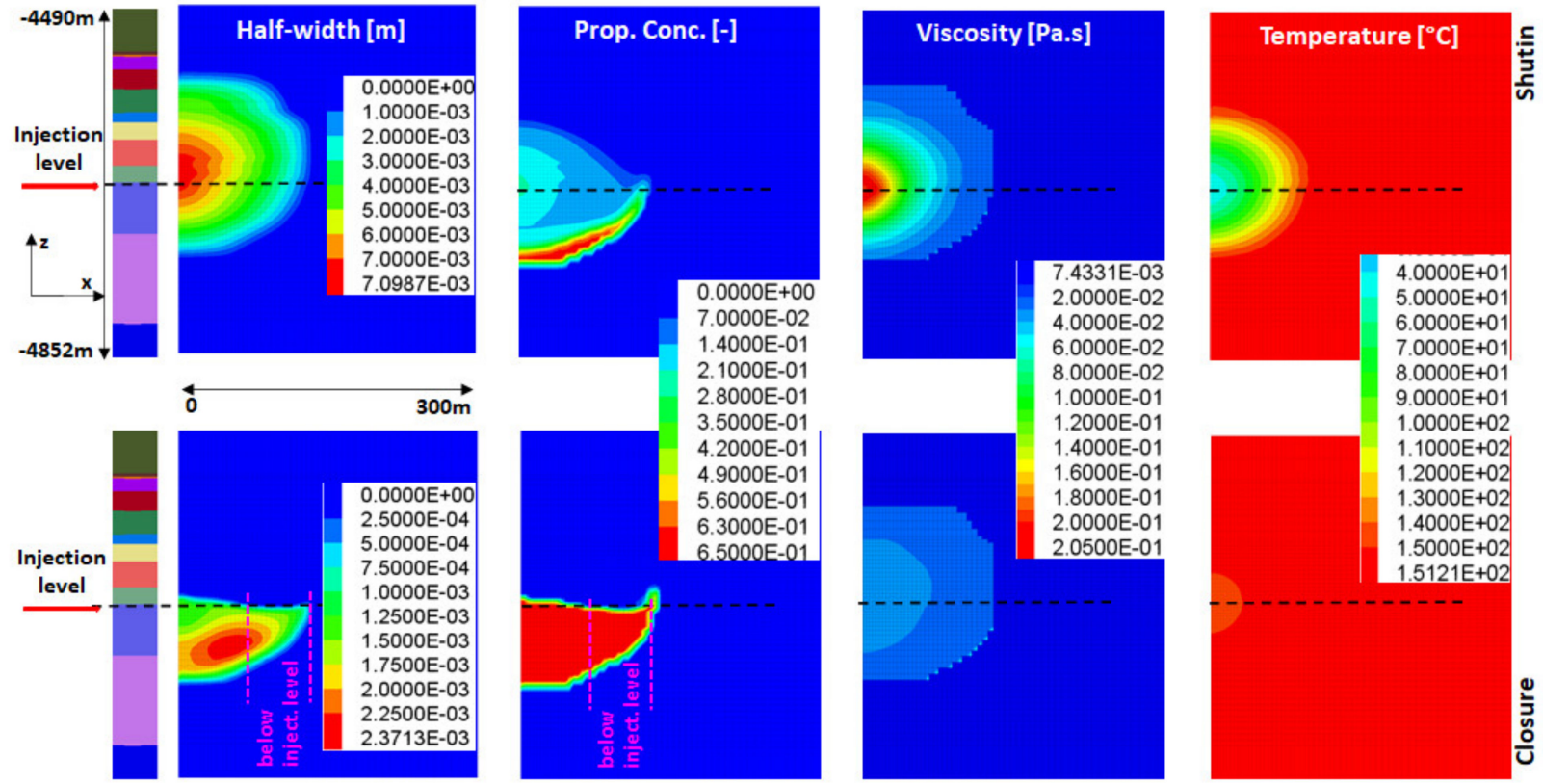

Figure 17. Fracture half-width, proppant concentration, viscosity, and temperature profiles at shutin (150 mins) and closure (600 mins).

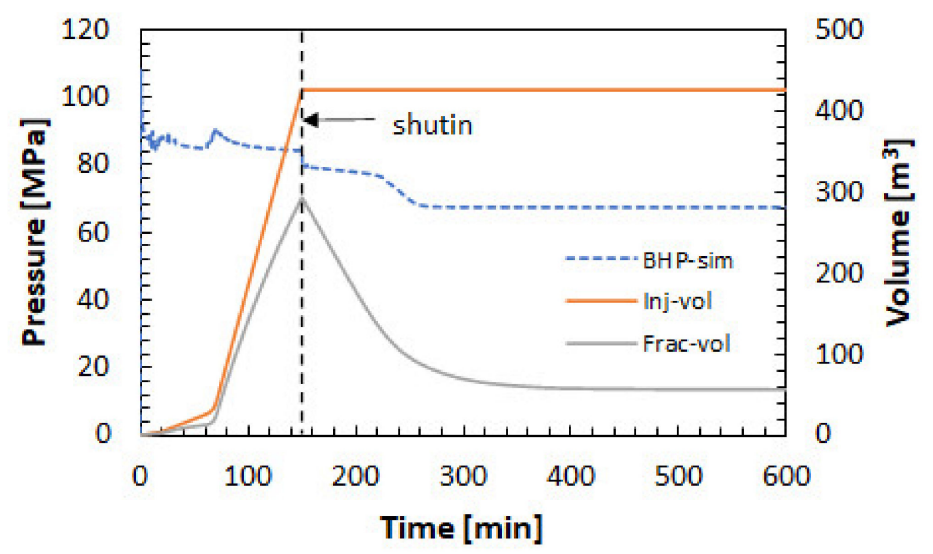

Figure 18. Injection and fracture volume.

\subsection{Sensitivity Analysis with N-Heptane as Frac-Fluid}

To understand the effect of important parameters such as injection rate, fluid viscosity, and injection time on hydraulic fracturing with n-heptane, simulation tests were performed with the help of a developed numerical model. For the case of proposed fluid injection, a hybrid fluid concept was utilized and fracturing was initiated with a small volume of water.

The utilized parameters of relative permeability and capillary pressure function are presented in Table 5 .

Table 5. Relative permeability and capillary pressure parameters for three-phase multi-component flow of fluid.

\begin{tabular}{cccc}
\hline \multicolumn{2}{c}{ Relative Permeability [41,47] } & \multicolumn{2}{c}{ Capillary Pressure $[41,48]$} \\
\hline $\mathrm{S}_{\mathrm{rg}}$ & 0.04 & $\alpha_{\text {ga }}$ & 11 \\
$\mathrm{~S}_{\mathrm{ra}}$ & 0.05 & $\alpha_{a w}$ & 12 \\
$\mathrm{~S}_{\mathrm{rw}}$ & 0.32 & $\mathrm{n}$ & 1.84 \\
$\mathrm{n}$ & 3 & $\mathrm{~m}$ & 0.45 \\
\hline
\end{tabular}




\subsubsection{Injection Rate}

Three different injection rates of 4,6 and $8 \mathrm{~m}^{3} / \mathrm{min}$ were considered to analyze their effect on fracture propagation. The injection program is discussed in Table 6.

Table 6. Proposed fluid injection schedule for injection rate sensitivity.

\begin{tabular}{cc}
\hline & Injection Schedule (75 min) \\
\hline $0-8 \mathrm{~min}$ & Water \\
$8-30 \mathrm{~min}$ & Light -heptane \\
$30-75 \mathrm{~min}$ & Gelled n-heptane $(0.15 \mathrm{~Pa} \cdot \mathrm{s})$ \\
\hline
\end{tabular}

The increase in injection rate increased the stimulated reservoir volume (Figure 19a, b). By looking at the fracture width, volume, half-length and height, it becomes clear that doubling the injection rate from 4 to $8 \mathrm{~m}^{3} / \mathrm{min}$ almost tripled the fracture volume with more fracture half-length, height and width. As it was not an ultra-tight gas reservoir, the leakoff of injected fluid was higher. At lower injection rates, fluid had more time to percolate into the surrounding matrix, resulting in lower fracture volume. Therefore, increasing the injection rate increased the fracturing rate. In addition, injecting gelled fluid from the beginning will also reduce excessive fluid leakoff.
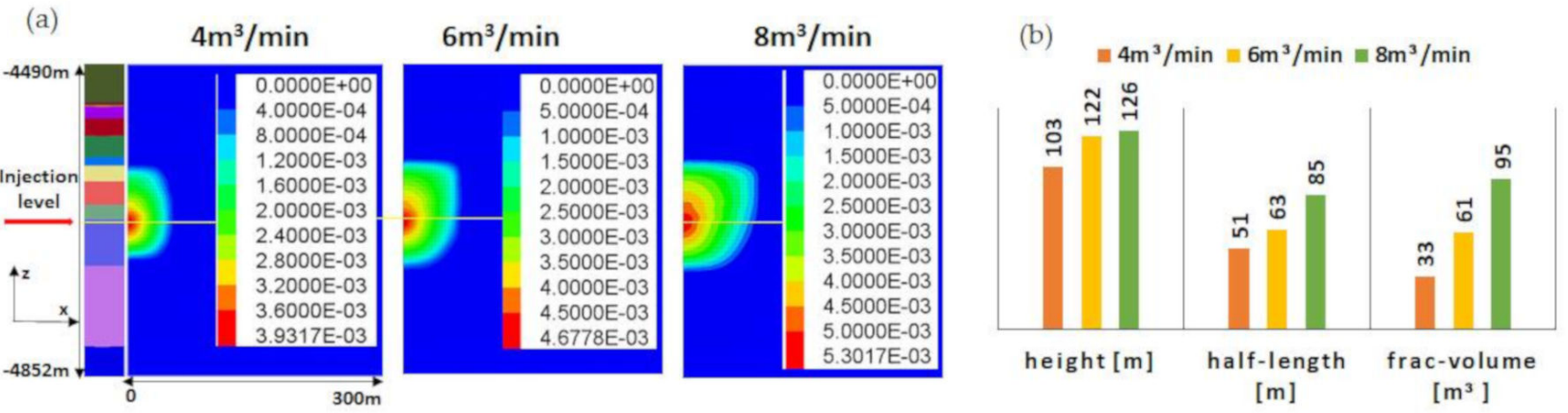

Figure 19. The (a) fracture half-width $(\mathrm{m})$ profiles for $4-6-8 \mathrm{~m}^{3} / \mathrm{min}$ injection rates at the end of injection, and (b) fracture height, half-length and volume for injection rates $4-6-8 \mathrm{~m}^{3} / \mathrm{min}$.

\subsubsection{Fluid Viscosity}

Fluid viscosity is a major parameter which affects the hydraulic fracturing job. To investigate this, fracturing was performed for $0.15 \mathrm{~Pa} \cdot \mathrm{s}, 0.25 \mathrm{~Pa} \cdot \mathrm{s}, 0.35 \mathrm{~Pa} \cdot \mathrm{s}$ and $0.45 \mathrm{~Pa} \cdot \mathrm{s}$ fluids at injection rates of $6 \mathrm{~m}^{3} / \mathrm{min}$ and $8 \mathrm{~m}^{3} / \mathrm{min}$ (Table 7). As was expected, increasing viscosity increased the simulated reservoir volume, and fractures with maximum widths of $0.9-1.4 \mathrm{~cm}$ can be generated with higher injection rates and fluid viscosities (Figure 20).

Table 7. Injection strategy for fluid viscosity sensitivity analysis.

\begin{tabular}{cc}
\hline & Injection Schedule (75 min) \\
\hline $0-8 \mathrm{~min}$ & Gelled-water \\
$8-75 \mathrm{~min}$ & Gelled-n-heptane \\
\hline
\end{tabular}

\subsubsection{Injection Period}

The effect of injection time from $1.25-2 \mathrm{~h}$ with $0.15 \mathrm{~Pa} \cdot \mathrm{s}, 0.25 \mathrm{~Pa} \cdot \mathrm{s}$ and $0.35 \mathrm{~Pa} \cdot \mathrm{s}$ fluid viscosities at injection rates of $6 \mathrm{~m}^{3} / \mathrm{min}$ and $8 \mathrm{~m}^{3} / \mathrm{min}$ are considered in this section. An increase of about $15 \mathrm{~m}$ in half-length, with increasing injection time and viscosity, was observed (Figure 21). Similarly, an increase in fracture height of $16 \mathrm{~m}$ for $6 \mathrm{~m}^{3} / \mathrm{min}$ and $30 \mathrm{~m}$ for $8 \mathrm{~m}^{3} / \mathrm{min}$ was observed when the injection period was increased from 1.25 to $2 \mathrm{~h}$. For the case of $8 \mathrm{~m}^{3} / \mathrm{min}$ and $0.15 \mathrm{~Pa} \cdot \mathrm{s}$ fluid, a fracture half-length of $105 \mathrm{~m}$ and a height of 
$138 \mathrm{~m}$ was achieved at $1.75 \mathrm{~h}$. Further injection had no effect on the fracture geometry apart from increasing width. For $0.25 \mathrm{~Pa} \cdot \mathrm{s}$ and $0.35 \mathrm{~Pa} \cdot \mathrm{s}$ fluids, similar fracture heights of $154 \mathrm{~m}$ and $162 \mathrm{~m}$ at 1.75 and $2 \mathrm{~h}$ for an $8 \mathrm{~m}^{3} / \mathrm{min}$ injection rate, respectively, were obtained. For an injection rate of $6 \mathrm{~m}^{3} / \mathrm{min}$ and $0.15 \mathrm{~Pa} \cdot \mathrm{s}$ viscosity, $81 \mathrm{~m}$ half-length and $126 \mathrm{~m}$ fracture height fracture were created.

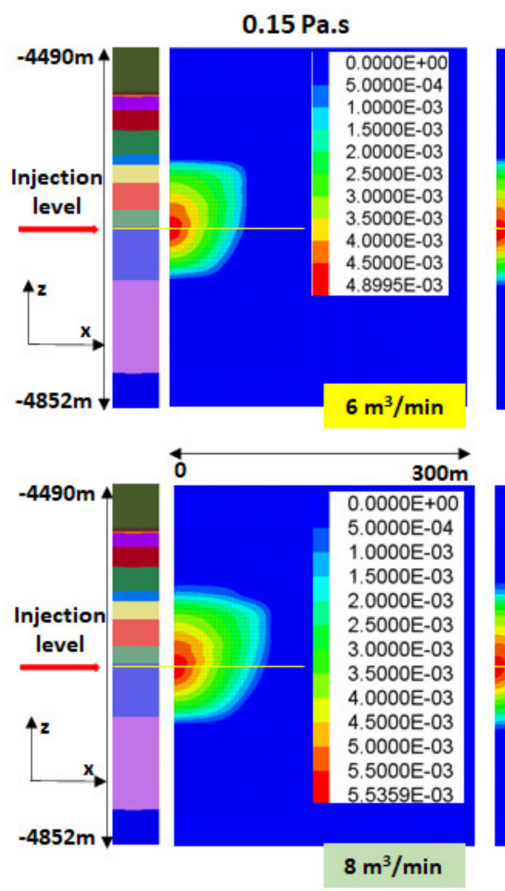

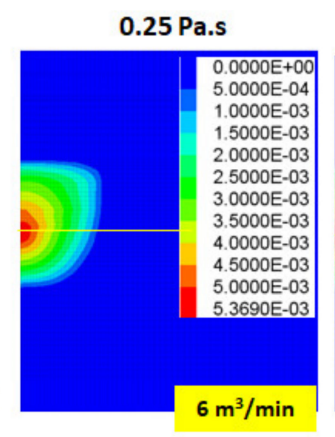

0.35 Pa.s
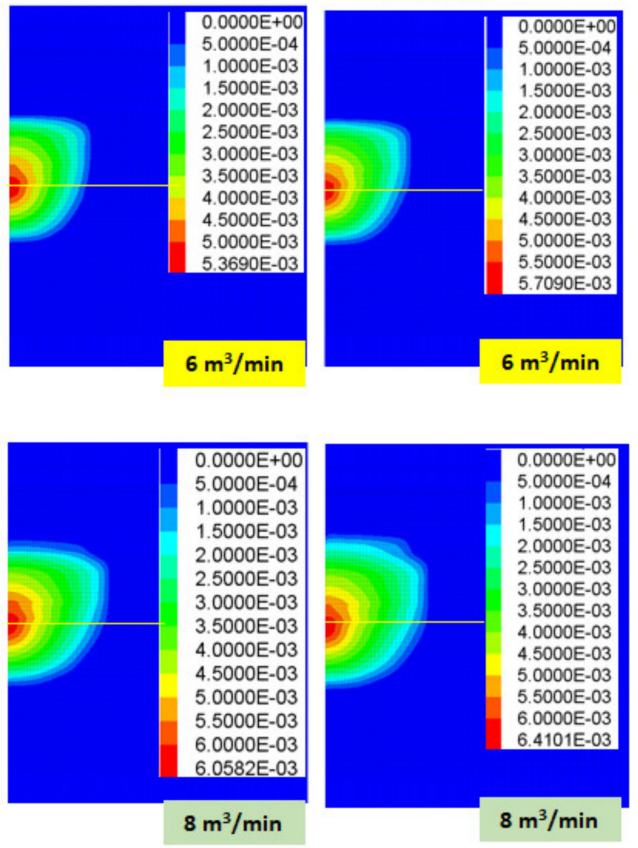
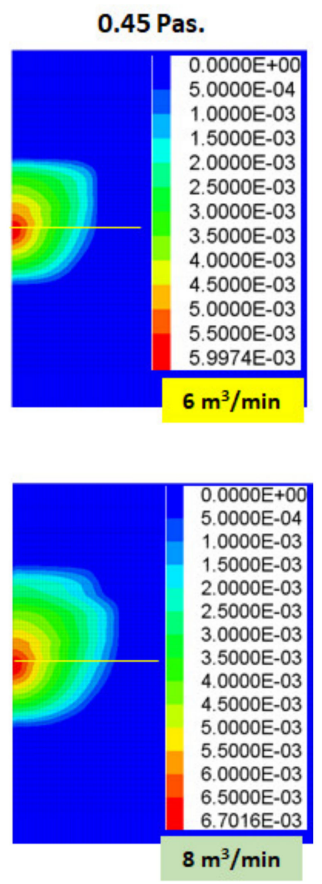

Figure 20. Fracture half-width $(\mathrm{m})$ for different injection strategies for different injection rates and fluid viscosities.

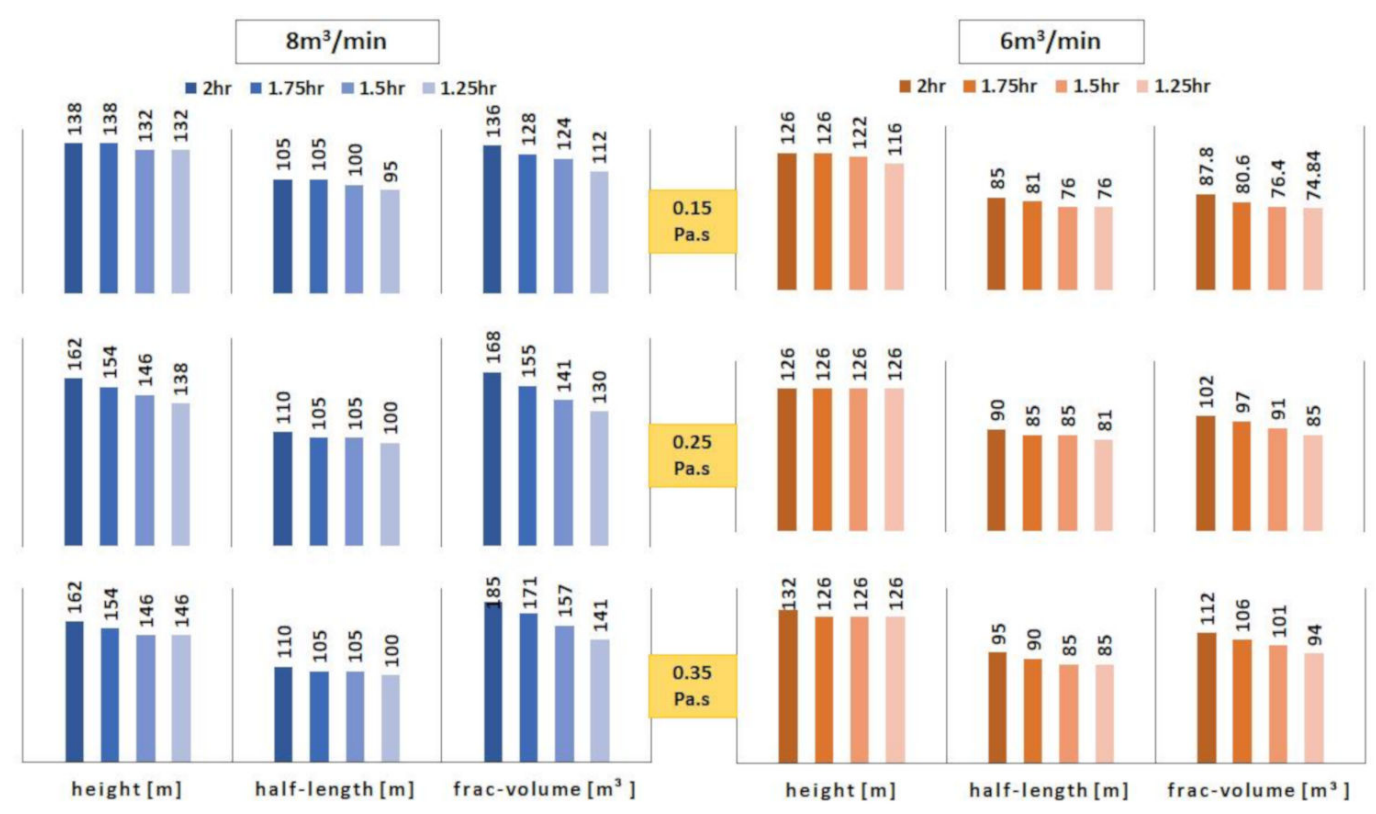

Figure 21. Fracture heights, half-lengths and volumes for different injection times for $0.15 \mathrm{~Pa} \cdot \mathrm{s}, 0.25 \mathrm{~Pa} \cdot \mathrm{s}$ and $0.35 \mathrm{~Pa} \cdot \mathrm{s}$ fluids at 6 and $8 \mathrm{~m}^{3} / \mathrm{min}$ injection rates.

\subsubsection{Reservoir Permeability}

Reservoir permeability is an uncontrollable factor which significantly affects fracture propagation and geometry. In ultra-tight reservoirs, the leakoff of the fluid, especially those 
like the proposed fluid, will be very low due to formation tightness. Resultantly, larger stimulated reservoir volumes, compared to tight or less tight reservoirs, can be generated. Low viscosity fluid at lower injection rates can be utilized in such reservoirs. Three cases are presented in this regard (Table 8). Two cases, case 1 and case 2, bear the original reservoir properties with the only difference being in the fluid injection schedule. In case 2, all gelled fluid was injected, but in case 1 pure fluids and then gelled fluid were injected. In case 3 , reservoir permeability was reduced by a factor of 0.01 , while maintaining the injection program of case 1 .

Table 8. Scenarios for the effect of reservoir permeability on fracture growth.

\begin{tabular}{cc}
\hline $\mathbf{7 5} \mathbf{~ m i n}\left(\mathbf{3 0 0} \mathbf{~ m}^{\mathbf{3}}\right.$ Injected at $\left.\mathbf{4} \mathbf{~ m}^{3} / \mathbf{m i n}\right)$ \\
\hline Original-1 & Water + n-heptane + gelled fluid n-heptane $(0.15 \mathrm{~Pa} \cdot \mathrm{s})$ \\
Original-2 & Gelled water + gelled n-heptane $(0.15 \mathrm{~Pa} \cdot \mathrm{s})$ \\
Permeability $\times 0.01\left[\mathrm{~m}^{2}\right]$ & Water + n-heptane + gelled n-heptane $(0.15 \mathrm{~Pa} \cdot \mathrm{s})$ \\
\hline
\end{tabular}

A significant increase to a fracture half-length of $149 \mathrm{~m}$ in case 3, from $51 \mathrm{~m}$ and $55 \mathrm{~m}$ in case 1 and 2, respectively, was found. Similarly, an almost 500\% increase in fracture volume for case 3 was observed (Figure 22a,b).
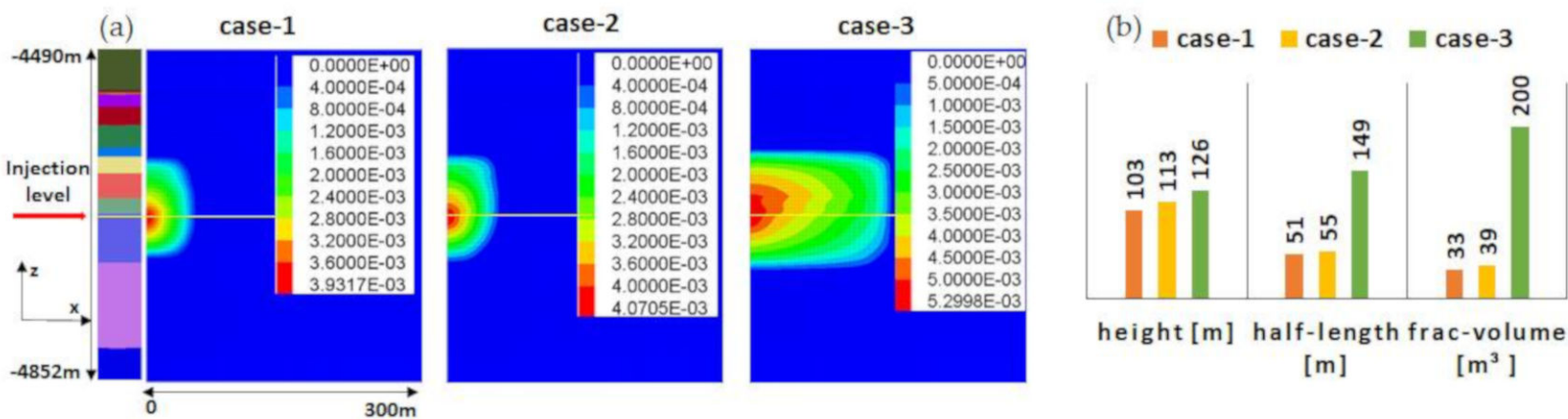

Figure 22. The (a) fracture half-width (m) for the three cases, and (b) fracture height, half-length and volume.

Figure 23 provides the trends of the fracture volume for the different cases. For case 1 , when pure fluids were injected initially, very little fracture volume was created as most of the injected fluid was lost to the formation. In case 2, only high viscosity fluid was injected, therefore, a slightly higher fracture volume was generated. Above all, the largest fracture volume of $200 \mathrm{~m}^{3}$ was generated with lowest leakoff in case 3 due to the lower leakoff. Therefore, pure fluid at lower injection rates can be utilized in such reservoirs for fracturing.

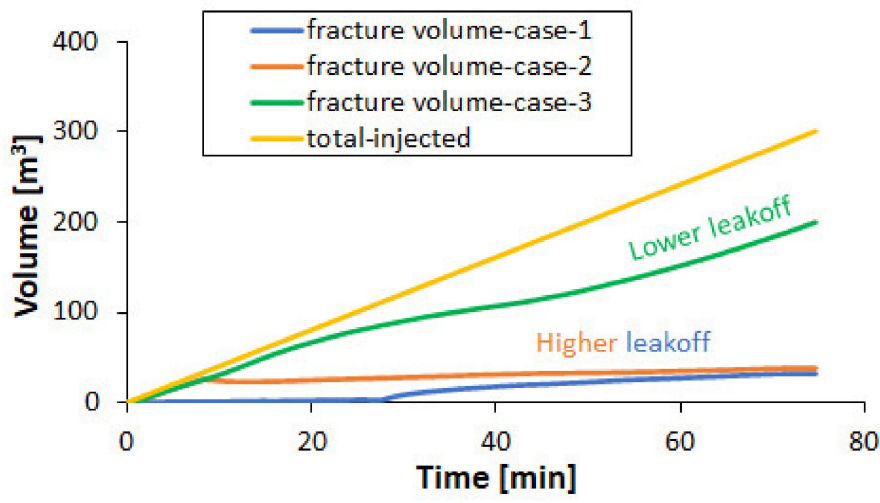

Figure 23. Injection and fracture volumes for different cases. 


\subsubsection{Fluid Flowback}

To perform the fluid flowback analysis, proppants were injected so that the fracture did not completely close upon shutin. An injection rate of $4.89 \mathrm{~m}^{3} / \mathrm{min}$ was maintained for 77 min, during which $375 \mathrm{~m}^{3}$ of injection fluid and 67 tons of proppant were injected. The details of fluid injection schedule are provided in Table 9.

Table 9. Injection schedule for conventional water-based and proposed hybrid fluid fracking.

\begin{tabular}{|c|c|c|c|c|c|c|c|}
\hline \multicolumn{4}{|c|}{ 1. Conventional $\left(375 \mathrm{~m}^{3}\right)$} & \multicolumn{4}{|c|}{ 2. Hybrid-N-Heptane $\left(375 \mathrm{~m}^{3}\right.$ ) } \\
\hline & $\begin{array}{l}\text { Injection } \\
\text { Fluid }\end{array}$ & $\begin{array}{c}\text { Total } \\
\text { Injected }\left(\mathrm{m}^{3}\right)\end{array}$ & $\begin{array}{l}\text { Injection } \\
\text { Time (min) }\end{array}$ & & Injection Fluid & $\begin{array}{c}\text { Total } \\
\text { Injected }\left(\mathrm{m}^{3}\right)\end{array}$ & $\begin{array}{l}\text { Injection } \\
\text { Time (min) }\end{array}$ \\
\hline Stage-1 & Water & 195 & $0-40$ & Stage-1 & Water & 30 & $0-6$ \\
\hline Stage-2 & Gelled-water & 180 & $40-77$ & Stage-2 & n-heptane & 166 & $6-40$ \\
\hline & & & & Stage-3 & Gelled n-heptane & 179 & $40-77$ \\
\hline
\end{tabular}

Figure 24 presents fluid injection rate and proppant schedule. Proppant injection reached a maximum of $5.42 \mathrm{ppg}\left(=650 \mathrm{~kg} / \mathrm{m}^{3}\right)$ at the end of injection, after which the pumping was stopped.

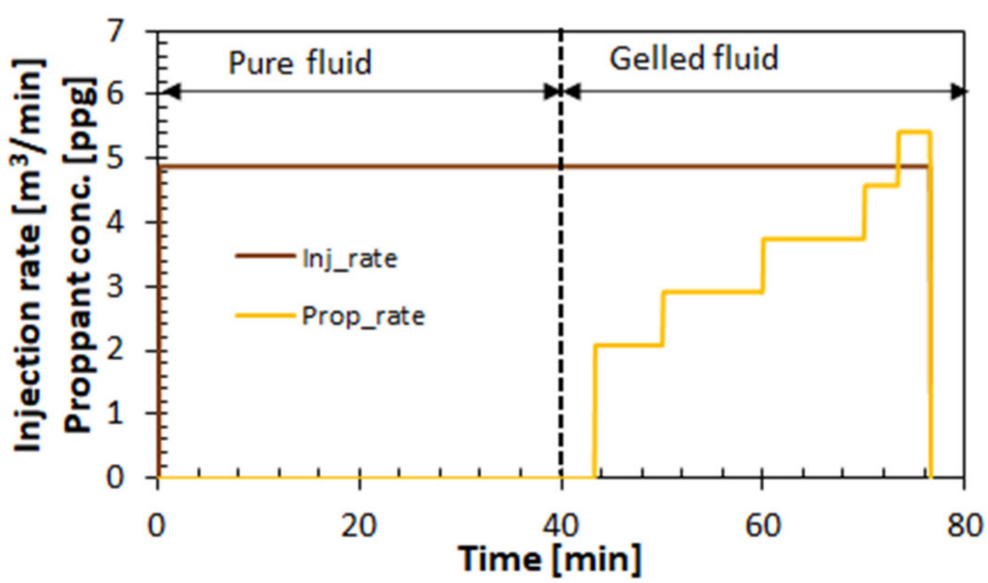

Figure 24. Fluid and proppant injection schedule.

Figure 25 shows the fracture and injection volume of the fracking operation. The fracture closure for the water-based fracture took place at about $400 \mathrm{~min}$, whereas the fracture closed at $150 \mathrm{~min}$ for $\mathrm{n}$-heptane. Due to the difference in heat capacities and volatility, the hybrid fluid caused quicker fracture closure, which could lead to better proppant placement, especially in the upper half of the fracture.

After the fracture closure, the flowback was carried out for a period of 7 days. The reservoir gas and injected frac-fluid saturation on day one and seven days after the hydraulic fracturing operation can be observed in Figure 26. As can be seen from saturation contours, most of the injected conventional fluid (water-based) remained in the reservoir even after seven days of flow back. In contrast, most of the alternative fluid (n-heptane) had flowed back from the propped fracture zone when the reservoir gas had reached maximum saturation (red contour: $95 \%$ ). Since n-heptane is hydrocarbon and a petroleum product, the phase trapping was minimized and, due to the lower viscosity and density, the flowback was quick, resulting in an efficient fracking job. The speedy flowback of the proposed fluid ensures early production of reservoir gas as compared to conventional fluids [22]. 


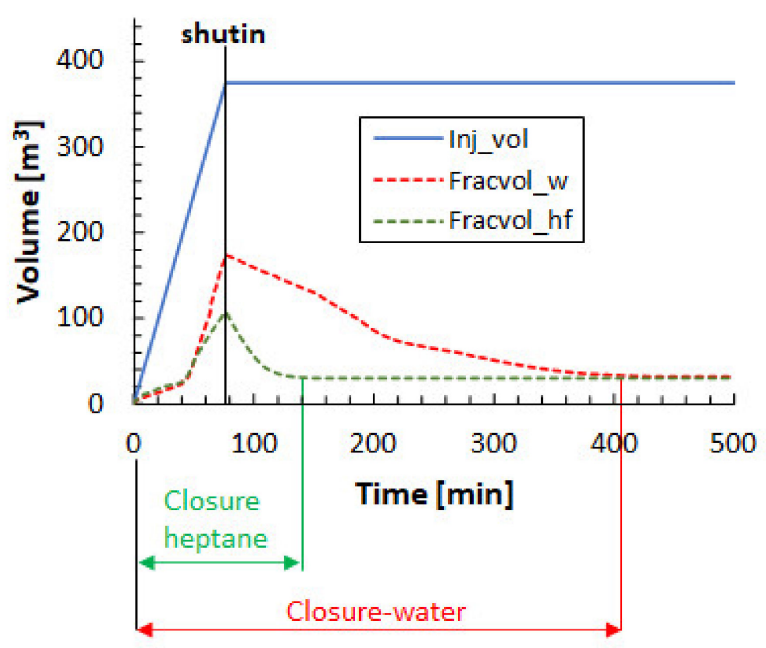

Figure 25. Fracture volume for the two cases at different times; w: water-based, and hf: n-heptane hybrid fluid.

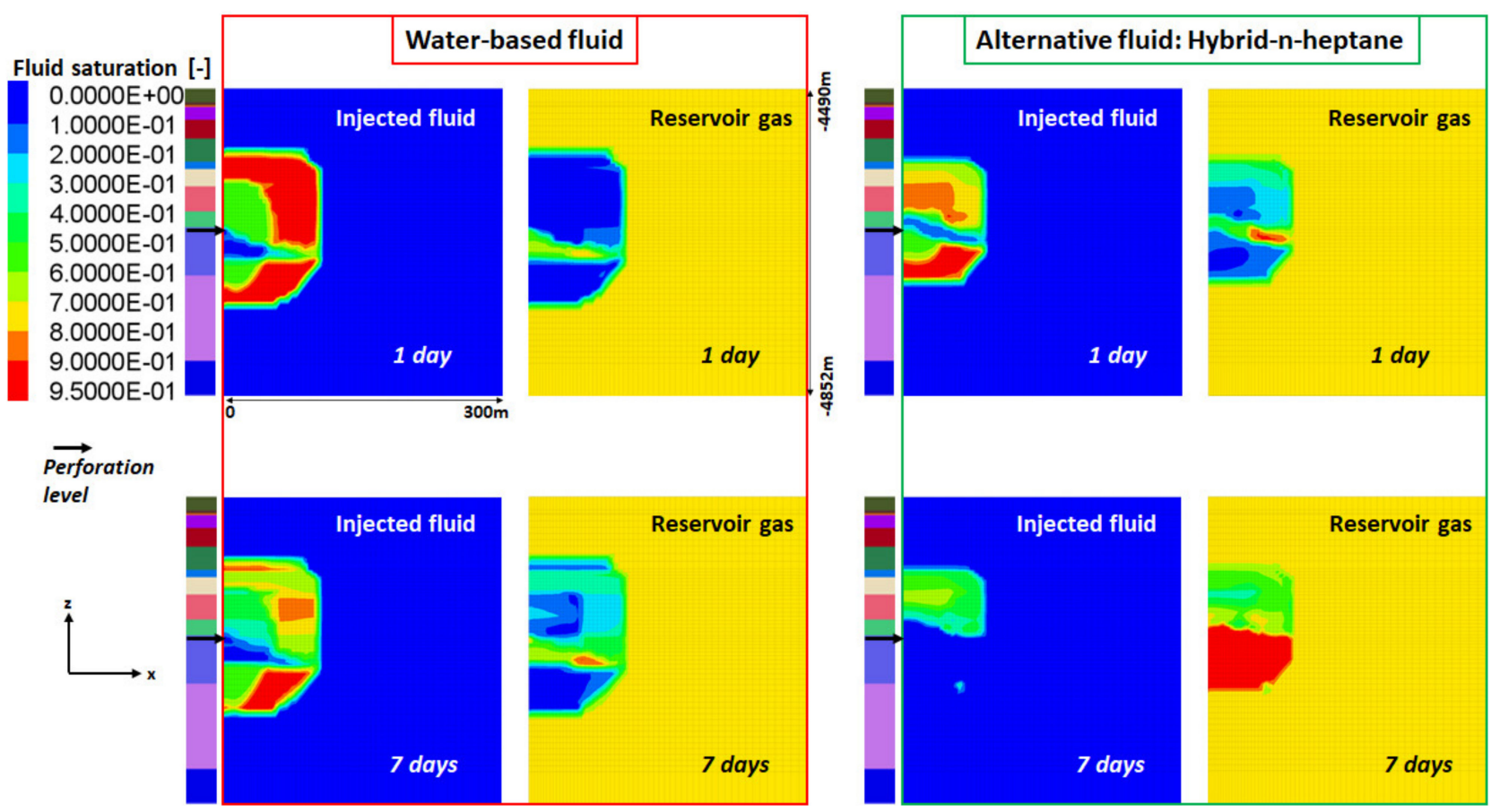

Figure 26. Saturation contours of reservoir gas and injection fluids after one and seven days of flowback.

\subsection{Design Proposals}

Generally, stimulation treatments are designed according to fracture conductivity. The higher the fracture conductivity, the better the wellbore productivity due to the ease of fluid flow. The dimensionless fracture conductivity is the ratio of the ability of the fracture to transmit the fluid to the ability of reservoir formation to feed the fracture (Equation (26)) [53].

$$
F_{c d}=\frac{k_{f} w}{k x_{f}}
$$

Dimensionless fracture conductivity has been utilized in the petroleum industry for designing hydraulic fracturing operations. However, they cannot identify the impact of hydraulic connection between propped fracture and perforations on conductivity. Therefore, a better technique would be to include the position and concentration of proppants with 
reference to injection level (perforations) for predicting the fracture conductivity. Recently, Hou et al. presented the weighted fracture conductivity (Equation (27)) which includes the proppant placement with reference to injection level [54]. However, it can be considered a conservative approach.

$$
F_{C D, \text { weighted }}=\frac{\sum_{i=1}^{n} \frac{w_{i} k_{f i}}{d_{i}} A_{i} \frac{c_{p}}{c_{\max }}}{\sum_{i=i}^{n} \frac{1}{d_{i}} A_{i} \frac{c_{p}}{c_{\max }}} \times \frac{1}{k x_{f}}
$$

where, $w$ : fracture width $(\mathrm{m}) ; k_{f}$ : fracture permeability $\left(\mathrm{m}^{2}\right) ; d$ : distance between fracture element and perforation $(\mathrm{m}) ; A$ : fracture element area $\left(\mathrm{m}^{2}\right) ; c_{p}$ : proppant concentration $(-) ; c_{\text {max }}$ : maximum proppant concentration; $k$ : reservoir permeability $\left(\mathrm{m}^{2}\right) ; x_{f}$ : fracture half-length $(\mathrm{m})$ and $n$ : total fracture elements (-).

From the outcome of the sensitivity analysis, hydraulic fracturing with gelled nheptane (0.15 Pa.s) and injection rates of $6-8 \mathrm{~m}^{3} / \mathrm{min}$ for a duration of 105 min were proposed. Two fracture designs are presented in this paper, in which fractures with weighted dimensionless conductivity of 30 and 44 are created with n-heptane. Due to quick fracture closure and leakoff, better proppant placement and improved borehole-fracture hydraulic connection was established in comparison with previous frac job. The fracture geometry and design parameters are presented in Figure 27.

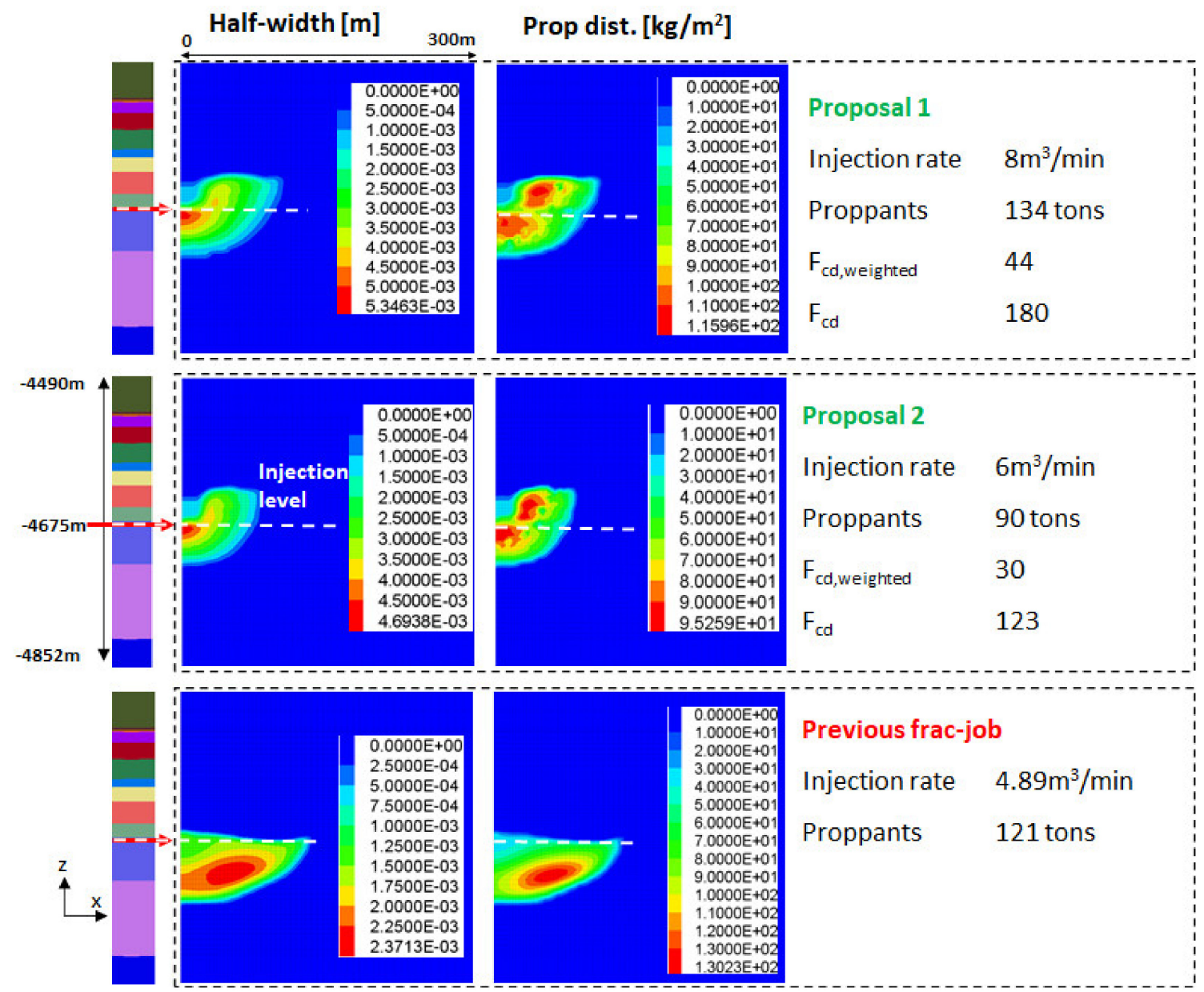

Figure 27. Fracture geometry and design for design proposals and previous fracture job.

At this point, it is important to address the economic considerations regarding the field application of n-heptane (or light alkanes) as a frac-fluid. Studies for the application of hydrocarbon-based fluids have demonstrated economically attractive prospects and 
shown that comparable or even lower costs will be incurred in comparison with waterbased fluids due to lower well cleanup requirements, better flowback ability, less additives, injection fluid flowback, reuse or sale, no special disposal requirements, and increased productivity [22,55-60]. Moreover, unlike gas-based hydrocarbon fluids such as LPG, there is no need for compression for liquification for the fluid reuse [61]. The boiling point of $\mathrm{n}$-heptane is $371.6 \mathrm{~K}$, therefore, it can be separated from the gas production stream as a liquid at the surface.

\section{Discussion}

In this research, a new MM numerical model to perform hydraulic fracturing operation with n-heptane in a 3D stress state was implemented and verified. Three-phase relative permeability and capillary pressure functions were utilized. The model was then applied to a wellbore $\mathrm{x}$ in a tight gas field in Germany. After the verification of the model through pressure history match with a previous fracture job, it was found that inadequate boreholefracture hydraulic connection could be created, which can be a major reason behind less recovery. Sensitivity analysis was performed for hydraulic stimulation with n-heptane and the effect of different parameters, such as fluid viscosity, injection rate and reservoir permeability, were analyzed. To avoid excessive leakoff, gelled fluid injection from the beginning of the operation is beneficial. However, higher fluid leakoff is beneficial for quick fracture closure after shutin to hold support agents (proppants) in the upper half of fracture to maintain adequate borehole-fracture connection.

A higher viscosity fluid will generate more fracture width, which may end in less propped fracture heights as a larger width fracture will require more time to close, giving a longer time for proppants to settle at the bottom of fracture due to gravity. Therefore, a reasonable viscosity fluid (such as $0.15 \mathrm{~Pa} \cdot \mathrm{s}$ ), to avoid excessive leakoff and create sufficient width for better proppant placement, is desirable.

Increasing the injection rate increases the fracturing rate compared to leakoff rate. Thus, fractures with half-lengths more than $100 \mathrm{~m}$ can be created with an $8 \mathrm{~m}^{3} / \mathrm{min}$ injection rate. The leakoff is low in ultra-tight reservoirs, so pure n-heptane can be utilized for fracture propagation and the gelled fluid may be required for the proppant transport period.

The comparison between flowback of the proposed and conventional water-based fluids has shown encouraging results, where it is possible to recover almost $100 \%$ of the alternative frac-fluid within a few days of flowback from the propped zones. This means that the reservoir gas production can start as early as the first day of flowback. Another reason for early reservoir gas production is because of the hydrocarbon nature of n-heptane which is an alkane, like natural gas. Therefore, phase trapping of injected fluid can be largely minimized due to its compatibility.

The design proposals put together from sensitivity analysis can help optimize wellbore $x^{\prime}$ s performance. Proposal 1, with an injection rate of $8 \mathrm{~m}^{3} / \mathrm{min}$, can generate a fracture with weighted dimensionless conductivity of 44 (Fcd: 180) and more than $100 \mathrm{~m}$ half-length fracture. While proposal 2, with a lower injection rate (i.e., $6 \mathrm{~m}^{3} / \mathrm{min}$ ), can create weighted dimensionless fracture conductivity of 30 (Fcd: 123). In both designs, excellent hydraulic connection between borehole and fracture is predicted.

\section{Conclusions}

With attributes of quick fracture closure, better propped fracture height, minimizing phase trapping and quick flowback, the proposed fluid is recommended for hydraulic fracturing operations in tight and ultra-tight gas reservoirs. However, based upon sensitivity analysis, higher injection rates, such as $6-8 \mathrm{~m}^{3} / \mathrm{min}$, and injecting gelled fluid will result in frac jobs with better fracture geometries in wellbore $\mathrm{x}$. The alternative frac-fluid can be chosen according to different reservoir conditions and desired fracture geometry and conductivity. The developed numerical model with the capability to simulate hydraulic fracturing process in full 3D approach with MM fluid flow can be utilized to 
perform hydraulic stimulation with a variety of injection fluids. By promoting the use of alternative fluids, environmental hazards associated with water-based fluids can be minimized, in addition to efficient hydraulic fracturing with better fracture conductivities and borehole-fracture connection. Fluid recovery and reuse for subsequent fracturing operations can make its application economically attractive and even comparable with conventional water-based fluid fracking.

The use of rod-shaped proppants in comparison with spherical proppants will be considered for improved fracture conductivity in the future work.

Author Contributions: Conceptualization, F.M. and M.Z.H.; methodology, F.M., and J.L. (Jianxing Liao); software, F.M., and J.L. (Jianxing Liao); validation, M.Z.H.; investigation, F.M., and J.L. (Jianxing Liao); writing-original draft preparation, F.M.; writing-review and editing, M.H., C.C., and J.L. (Jiashun Luo); supervision, M.Z.H. All authors have read and agreed to the published version of the manuscript.

Funding: This research was funded by the Deutsche Wissenschaftliche Gesellschaft für Erdöl, Erdgas und Kohle e.V.: DGMK-Project 814. The authors thank S. Kuchling (DGMK, Hamburg) for project coordination. We would like to express our gratitude to all the project partners for their support, guidance, and informative discussions: D. Leuchtmann (Wintershall Dea GmbH, Hamburg), M. Zinterl (ExxonMobil Production Deutschland GmbH, Hanover), M. Berling (Neptune Energy Deutschland $\mathrm{GmbH}$, Lingen) and J. Sommer (Wintershall Dea $\mathrm{GmbH}$, Kassel). We are especially thankful to M. Zinterl (ExxonMobil Production Deutschland $\mathrm{GmbH}$, Hanover) for providing the case study data.

Institutional Review Board Statement: Not applicable.

Informed Consent Statement: Not applicable.

Data Availability Statement: Not applicable.

Conflicts of Interest: The authors declare no conflict of interest.

\section{References}

1. Prud'homme, A. Hydrofracking: What Everyone Needs to Know; Oxford University Press: New York, NY, USA, 2013.

2. Montgomery, C.T.; Smith, M.B. Hydraulic fracturing: History of an enduring technology. J. Pet. Technol. 2010, 62, 26-40. [CrossRef]

3. Rahm, D. Regulating hydraulic fracturing in shale gas plays: The case of Texas. Energy Policy 2011, 39, 2974-2981. [CrossRef]

4. Liu, Y.; Leung, J.Y.; Chalaturnyk, R. Geomechanical Simulation of Partially Propped Fracture Closure and Its Implication for Water Flowback and Gas Production. SPE Reserv. Eval. Eng. 2018, 21, 273-290. [CrossRef]

5. Alexander, T.; Baihly, J.; Boyer, C.; Clark, B.; Waters, G.; Jochen, V. Shale Gas Revolution. Oilfield Rev. 2011, $23,40-55$.

6. Howarth, R.W.; Ingraffea, A.; Engelder, T. Should fracking stop? Nature 2011, 477, 271-275. [CrossRef]

7. Hughes, J.D. A reality check on the shale revolution. Nature 2013, 94, 307-308. [CrossRef]

8. Clark, J.B. A Hydraulic Process for Increasing the Productivity of Wells. J. Pet. Technol. 1949, 1, 1-8. [CrossRef]

9. Fisher, M.K.; Warpinski, N.R. Hydraulic-Fracture-Height Growth: Real Data. SPE Prod. Oper. 2012, 27, 8-19. [CrossRef]

10. Rubinstein, J.L.; Mahani, A.B. Myths and Facts on Wastewater Injection, Hydraulic Fracturing, Enhanced Oil Recovery, and Induced Seismicity. Seismol. Res. Lett. 2015, 86, 1060-1067. [CrossRef]

11. Gallegos, T.J.; Varela, B.A. Trends in Hydraulic Fracturing Distributions and Treatment Fluids, Additives, Proppants, and Water Volumes Applied to Wells Drilled in the United States from 1947 through 2010-Data Analysis and Comparison to the Literature; US Geological Survey Scientific Investigations Report; USGS: Reston, VA, USA, 2015; pp. 2014-5131.

12. Gallegos, T.J.; Varela, B.A.; Haines, S.S.; Engle, M.A. Hydraulic fracturing water use variability in the United States and potential environmental implications. Water Resour. Res. 2015, 51, 5839-5845. [CrossRef]

13. Kondash, A.; Vengosh, A. Water Footprint of Hydraulic Fracturing. Environ. Sci. Technol. Lett. 2015, 2, 276-280. [CrossRef]

14. US EPA. Hydraulic Fracturing for Oil and Gas: Impacts from the Hydraulic Fracturing Water Cycle on Drinking Water Resources in the United States; Final Report EPA/600/R-16/236F; National Center for Environmental Assessment, US Environmental Protection Agency: Washington, DC, USA, 2016.

15. Jacobs, T. Energized Fractures: Shale Revolution Revisits the Energized Fracture. J. Pet. Technol. 2014, 66, 48-56. [CrossRef]

16. Vengosh, A.; Jackson, R.B.; Warner, N.; Darrah, T.H.; Kondash, A. A Critical Review of the Risks to Water Resources from Unconventional Shale Gas Development and Hydraulic Fracturing in the United States. Environ. Sci. Technol. 2014, 48, 8334-8348. [CrossRef]

17. Elliott, E.G.; Ettinger, A.S.; Leaderer, B.P.; Bracken, M.B.; Deziel, N.C. A systematic evaluation of chemicals in hydraulic-fracturing fluids and wastewater for reproductive and developmental toxicity. J. Expo. Sci. Environ. Epidemiol. 2017, 27, 90-99. [CrossRef]

18. Li, S.; Zhang, D. How Effective Is Carbon Dioxide as an Alternative Fracturing Fluid? SPE J. 2019, 24, 857-876. [CrossRef] 
19. Sanaei, A.; Shakiba, M.; Varavei, A.; Sepehrnoori, K. Mechanistic Modeling of Clay Swelling in Hydraulic-Fractures Network. SPE Res. Eval. Eng. 2018, 21, 96-108. [CrossRef]

20. Bennion, D.B.; Thomas, F.B.; Bietz, R.F.; Bennion, D.W. Water and Hydrocarbon Phase Trapping in Porous Media-Diagnosis, Prevention and Treatment. J. Can. Pet. Technol. 1996, 35, 29-36. [CrossRef]

21. Zhang, J.; Zhu, D.; Hill, A.D. Water-Induced Damage to Propped-Fracture Conductivity in Shale Formations. SPE Prod. Oper. 2016, 31, 147-156. [CrossRef]

22. Leblanc, D.P.; Martel, T.; Graves, D.G.; Tudor, E.; Lestz, R. Application of Propane (LPG) Based Hydraulic Fracturing in the McCully Gas Field, New Brunswick, Canada. In Proceedings of the North American Unconventional Gas Conference and Exhibition, The Woodlands, TX, USA, 14-16 June 2011. [CrossRef]

23. Gandossi, L.; Estorff, U.V. An Overview of Hydraulic Fracturing and other Formation Stimulation Technologies for Shale Gas ProductionUpdate 2015; EUR 26347; JRC Technical Report; European Commission: Luxembourg, 2015.

24. Kong, B.; Wang, S.; Chen, S. Minimize Formation Damage in Water-Sensitive Montney Formation with Energized Fracturing Fluid. SPE Res. Eval. Eng. 2017, 20, 562-571. [CrossRef]

25. Ortiz, J.; McLane, J.E. Low-pH Methanol: An Alternative for Stimulation in Water-Sensitive, Tight, Dirty Sandstones. SPE Prod. Eng. 1986, 1, 195-202. [CrossRef]

26. Hou, M.Z.; Mehmood, F. Numerical simulation of innovative fracking without water or chemical additives. Eur. Geol. J. 2018, 46, 17-23.

27. Mehmood, F.; Hou, M.Z.; Liao, J. Alternative frac-fluids: A step towards efficient and environment friendly fracking. Oil Gas Eur. Mag. 2020, 46, 33-40.

28. IPM Suite of Petroleum Engineering Software; Petroleum Experts: Edinburgh, UK, 2018.

29. API. API Tech Data Book 10; American Petroleum Institute: New York, NY, USA, 2016.

30. Fast Lagrangian Analysis of Continua in 3 Dimensions; Version 4.0; Itasca Consulting Group Inc.: Minneapolis, MN, USA, 2009.

31. Zhou, L.; Hou, M.Z. A new numerical 3D-model for simulation of hydraulic fracturing in consideration of hydro-mechanical coupling effects. Int. J. Rock Mech. Min. Sci. 2013, 60, 370-380. [CrossRef]

32. Zhou, L.; Hou, M.Z.; Gou, Y.; Li, M. Numerical investigation of a low-efficient hydraulic fracturing operation in a tight gas reservoir in the North German Basin. J. Pet. Sci. Eng. 2014, 120, 119-129. [CrossRef]

33. Zhou, L.; Gou, Y.; Hou, Z.; Were, P. Numerical modeling and investigation of fracture propagation with arbitrary orientation through fluid injection in tight gas reservoirs with combined XFEM and FVM. Environ. Earth Sci. 2015, 73, 5801-5813. [CrossRef]

34. Feng, W.; Were, P.; Li, M.; Hou, Z.; Zhou, L. Numerical study on hydraulic fracturing in tight gas formation in consideration of thermal effects and THM coupled processes. J. Pet. Sci. Eng. 2016, 146, 241-254. [CrossRef]

35. Rutqvist, J.; Wu, Y.-S.; Tsang, C.-F.; Bodvarsson, G. A modeling approach for analysis of coupled multiphase fluid flow, heat transfer, and deformation in fractured porous rock. Int. J. Rock Mech. Min. Sci. 2002, 39, 429-442. [CrossRef]

36. Rutqvist, J. Status of the TOUGH-FLAC simulator and recent applications related to coupled fluid flow and crustal deformations. Comput. Geosci. 2011, 37, 739-750. [CrossRef]

37. Pruess, K.; Oldenburg, C.; Moridis, G. TOUGH2 User's Guide, version 2; LBNL-43134; Lawrence Berkeley National Laboratory, Earth Sciences Division, University of California: Berkley, CA, USA, 1999.

38. Gou, Y.; Zhou, L.; Zhao, X.; Hou, Z.; Were, P. Numerical study on hydraulic fracturing in different types of georeservoirs with consideration of $\mathrm{H}^{2} \mathrm{M}$-coupled leak-off effects. Environ. Earth Sci. 2015, 73, 6019-6034. [CrossRef]

39. Li, M.; Hou, M.Z.; Zhou, L.; Gou, Y. Numerical Study of the Hydraulic Fracturing and Energy Production of a Geothermal Well in Northern Germany. In Proceedings of the ISRM European Rock Mechanics Symposium-EUROCK 2018, St. Petersburg, Russia, 22-26 May 2018.

40. Zhang, K.; Wu, Y.-S.; Pruess, K. User's Guide for TOUGH2-MP-A Massively Parallel Version of the TOUGH2 Code; LBNL-315E; Earth Sciences Division, Lawrence Berkeley National Laboratory: Berkley, CA, USA, 2008.

41. Pruess, K.; Battistelli, A. TMVOC, A Numerical Simulator for Three-Phase Non-isothermal Flows of Multicomponent Hydrocarbon Mixtures in Saturated-Unsaturated Heterogeneous Media; Lawrence Berkeley National Laboratory: Berkeley, CA, USA, 2002.

42. Fjaer, E.; Horsrud, P.; Raaen, A.M.; Risnes, R. Fracturing. In Petroleum Related Rock Mechanics; Elsevier: Amsterdam, The Netherlands, 1992; Volume 33, pp. 269-286.

43. Liao, J.; Hou, M.Z.; Mehmood, F.; Feng, W. A 3D approach to study the interaction between hydraulic and natural fracture. Environ. Earth Sci. 2019, 78, 681. [CrossRef]

44. Torres, M.D.; Hallmark, B.; Wilson, D.I. Effect of concentration on shear and extensional rheology of guar gum solutions. Food Hydrocoll. 2014, 40, 85-95. [CrossRef]

45. Zhang, L.-M.; Kong, T.; Hui, P.S. Semi-dilute solutions of hydroxypropyl guar gum: Viscosity behaviour and thixotropic properties. J. Sci. Food Agric. 2007, 87, 684-688. [CrossRef]

46. Barree, R.D.; Conway, M.W. Experimental and Numerical Modeling of Convective Proppant Transport (includes associated papers 31036 and 31068). J. Pet. Technol. 1995, 47, 216-222. [CrossRef]

47. Stone, H.L. Probability Model for Estimating Three-Phase Relative Permeability. J. Pet. Technol. 1970, 22, 214-218. [CrossRef]

48. Parker, J.C.; Lenhard, R.J.; Kuppusamy, T. A parametric model for constitutive properties governing multiphase flow in porous media. Water Resour. Res. 1987, 23, 618-624. [CrossRef] 
49. Tischner, T.; Krug, S.; Pechan, E.; Hesshaus, A.; Jatho, R.; Bischoff, M.; Wonik, T. Massive Hydraulic Fracturing in Low Permeable Sedimentary Rock in the GeneSys Project. In Proceedings of the Thirty-Eighth Workshop on Geothermal Reservoir Engineering, SGP-TR-198, Stanford University, Stanford, CA, USA, 11-13 February 2013.

50. Hou, M.Z.; Mehmood, F.; Liao, J. DGMK-Project 814: Numerical and Model-Physical Investigations on Innovative FracTechnologies with Alternative Frac-Fluids for Tight Gas Formations and Re-fracturing Options. In Proceedings of the DGMK/ÖGEW-Frühjahrstagung des Fachbereiches Aufsuchung und Gewinnung 2019-1, Celle, Germany, 25-26 April 2019; ISBN 978-3-941721-96-8.

51. Zhou, L. New Numerical Approaches to Model Hydraulic Fracturing in Tight Reservoirs with Consideration of Hydro-Mechanical Coupling Effects. Ph.D. Thesis, Clausthal University of Technology, Clausthal Zellerfeld, Germany, 5 March 2014.

52. Liao, J. Development of Coupled THM Models for Reservoir Stimulation and Geo-Energy Production with Supercritical $\mathrm{CO}_{2}$ as Working Fluid. Ph.D. Thesis, Clausthal University of Technology, Clausthal Zellerfeld, Germany, 30 June 2020.

53. Prats, M. Effect of Vertical Fractures on Reservoir Behavior-Incompressible Fluid Case. SPE J. 1961, 1, 105-118. [CrossRef]

54. Hou, M.Z.; Li, M.; Gou, Y.; Feng, W. Numerical simulation and evaluation of the fracturing and tight gas production with a new dimensionless fracture conductivity $\left(\mathrm{F}_{\mathrm{CD}}\right)$ model. Acta Geotech. 2020, 16, 985-1000. [CrossRef]

55. Perfetto, R.; Melo, R.C.B.; Martocchia, F.; Lorefice, R.; Ceccarelli, R.; Tealdi, L.; Okassa, F. Oil-based fracturing fluid: First results in West Africa onshore. In Proceedings of the International Petroleum Technology Conference, Beijing, China, 26-28 March 2013. [CrossRef]

56. Edwards, J.; Tudor, R.; Jones, D. Benefits of quality hydrocarbon fracturing fluid recycling. In Proceedings of the Canadian International Petroleum Conference, Calgary, AB, Canada, 16-18 June 2009. [CrossRef]

57. Hlidek, B.T.; Meyer, R.K.; Yule, K.; Wittenberg, J. A case for oil-based fracturing fluids in Canadian Montney unconventional gas development. In Proceedings of the SPE Annual Technical Conference and Exhibition, San Antonio, TX, USA, 8-10 October 2012. [CrossRef]

58. Cikes, M.; Cubric, S.; Moylashov, M.R. Formation damage prevention by using an oil-based fracturing fluid in partially depleted oil reservoirs of Western Siberia. In Proceedings of the SPE Formation Damage Control Conference, Lafayette, LA, USA, 18-19 February 1998. [CrossRef]

59. Almubarak, M.; Almubarak, T.; Ng, H.J.; Hernandez, J.; Nasr-El-Din, H. Recent advances in waterless fracturing fluids: A review. In Proceedings of the Abu Dhabi International Petroleum Exhibition \& Conference, Abu Dhabi, United Arab Emirates, 9-12 November 2020. [CrossRef]

60. Li, L.; Ozden, S.; Zhang, J.; Liang, F. Enhanced gelled hydrocarbon well treatment fluids. Petroleum 2020, 6, 177-181. [CrossRef]

61. Liew, M.S.; Danyaro, K.U.; Zawawi, N.A.W.A. A Comprehensive Guide to Different Fracturing Technologies: A Review. Energies 2020, 13, 3326. [CrossRef] 